
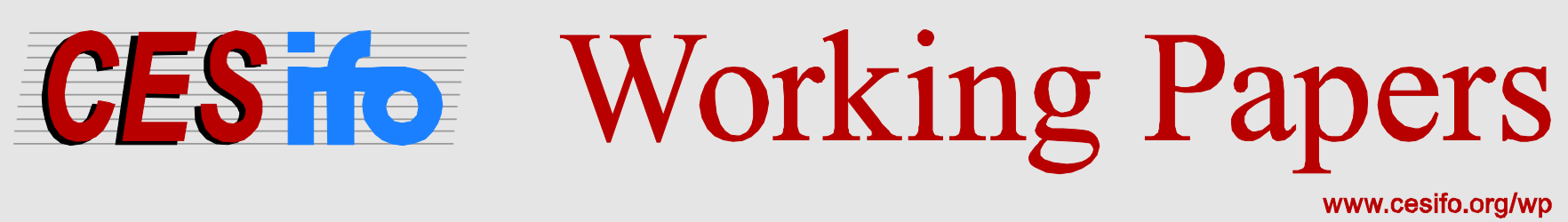

\title{
Optimal Organization of Financial Intermediaries
}

\author{
Spiros Bougheas \\ Tianxi Wang
}

\author{
CESIFO WORKING PAPER NO. 5452 \\ CATEGORY 7: MONETARY POLICY AND INTERNATIONAL FinANCE \\ JULY 2015
}

An electronic version of the paper may be downloaded

- from the SSRN website:

- from the RePEc website:

- from the CESifo website:

wWw.SSRN.com

www.RePEc.org

www.CESifo-group.org/wp 


\title{
Optimal Organization of Financial Intermediaries
}

\begin{abstract}
This paper provides a unified framework for endogenizing two distinct organizational structures of financial intermediation. In one structure, called Bank, the intermediary is financed by issuing debt contracts to investors, and thus resembles commercial banks. In the other structure, called Fund, the intermediary is financed by issuing equity contracts to investors, thus resembling private-equity funds. The paper finds that in the former incentives can be provided in a less costly way, but the latter is more robust to negative shocks on the asset side. Our model predicts that relative to banks, private equity funds are more involved in the running of the firms that they finance, contribute more to the success of these firms, and provide funds to higher-risk, higher-return firms.
\end{abstract}

JEL-Code: D860, G000.

Keywords: financial intermediation, bank, equity funds.

\author{
Spiros Bougheas \\ School of Economics \\ University of Nottingham \\ University Park \\ United Kingdom - Nottingham NG7 2RD \\ spiros.bouhjeas@nottingham.ac.uk
}

\author{
Tianxi Wang \\ Department of Economics \\ University of Essex \\ United Kingdom - Colchester, CO4 3SQ \\ wangt@essex.ac.uk
}

July 2015

We would like to thank John Moore, Daniel Seidmann, Silvia Sonderegger and seminar participants at the Centre of Finance Credit and Macroeconomics - University of Nottingham and Loughborough University for helpful comments and suggestions. 


\section{Introduction}

In economic environments where transaction costs, informational asymmetries and incomplete markets inhibit direct relationships between borrowers and lenders, financial intermediaries bring the two parties together. To a very large extent this intermediation role is performed by banks. A defining characteristic of banks is that on their liability side they raise funds mainly by offering fix obligations to investors (depositors). However, in the last twenty years, we have seen a rapid growth of an alternative class of financial intermediaries, namely, private equity funds, that, unlike banks, raise funds by offering equity claims to their investors who are known as limited partners (see Mertrick and Yasuda, 2010). Some types of private equity funds, like banks, finance a variety of new investments for firms unable to access directly the capital markets. For example, venture capital specializes in financing young, innovative firms, growth capital finances expansion activities of relatively mature firms, and mezzanine capital offers investors preferred equity to finance activities of small firms. ${ }^{1}$ The volume of capital managed by private equity funds has risen from $\$ 5$ billion in 1980 to $\$ 100$ billion in 1994 to about $\$ 1$ trillion in $2012 .^{2}$

The coexistence of two distinct organization structures for financial intermediation raises the following questions. What are the relative advantages of each structure? Taking into account the endogeneity of both structures, which types of firms are more likely to seek funding from each structure? We address these questions in a unified framework where depending on the values of parameters, the optimal equilibrium contractual arrangement corresponds to one of these two structures.

In our model, an intermediary that bridges entrepreneurs and many small investors provides a service that can potentially increase the probability of success of the projects that it finances. The range of activities that such a service can capture is broad, including consultation, marketing, and controlling entrepreneurial moral hazard, but following the literature we call it 'monitoring'. The provision of this monitoring service, however, is unobservable to the investors. As a result, the intermediary is liable to a moral hazard problem. So far, our model is similar to Holmström and Tirole (1997). The

\footnotetext{
${ }^{1}$ We are mainly concerned with intermediaries that finance new investment projects so we will ignore private equity funds specializing in leverage buyouts of established firms and other types of intermediaries that invest in financial assets such as hedge funds and mutual funds.

${ }^{2}$ The first couple of figures were taken from Fenn, Liang and Prowse (1995) while the last figure is reported in Metrick and Yasuda (2012). To put these figures in perspective, the total loans and leases granted to businesses and households by U.S. commercial banks form 1/10/2012 till 30/9/2012 according to FDIC was approximately $\$ 7$ trillion.
} 
innovation of our paper is that, after the funds have been invested, the projects are subject to a shock, observed by the intermediary, that divides them into two types: A type $h$ project can benefit from the intermediary's service while a type $l$ project cannot. Using a mechanism design approach we solve for the optimal contracts on both sides of the intermediary's balance sheet. We find that the equilibrium organization structure of financial intermediation can be of only two types, differing in the nature of securities they issue to investors. The securities are either debt contracts in which case we will refer to the organization structure as 'Bank', or equity contracts in which case we will refer to the organization structure as 'Fund'.

The trade-off between Bank and Fund is that while Bank has the advantage of providing incentives to the intermediary at a lower cost, Fund is more robust to negative realizations (type $l$ ) of the shock. In order to understand this trade-off, consider the case where the intermediary finances two projects that are both type $h$. Then, as Laux (2001) has demonstrated, the optimal incentive scheme features cross-pledging and pays the agent only when both projects succeed. This is implemented in our setting by the intermediary issuing a debt contract to investors which leaves the intermediary with nothing when only one project succeeds. Next, consider what happens when we introduce the shock which impacts the projects after the investments have been made. Suppose that one project is type $l$ and the other is type $h$. Further, suppose that the probability of success of either type $l$ projects or type $h$ projects that are not monitored is very close to zero. Under the debt contract the intermediary gets most likely nothing even if it increases the success probability of the type $h$ project through monitoring. Therefore, the intermediary has no incentives to monitor that project. Put differently, bad news about one project ruins incentives to monitor any of the projects. In contrast, suppose that the intermediary is financed with equity contracts. Whenever one project succeeds, the intermediary receives a share of the revenues from the successful project, which offers it incentives to monitor the type $h$ project thus increasing its success probability even if the other project is destined to fail. In summary, the Bank structure provides incentives at a lower cost, but the Fund structure is more robust to bad news. We show that this trade-off between Bank and Fund holds for a wide set of parameters and that the two organization structures are the only ones occurring in equilibrium.

The paper thus captures the commonly held view that equity enhances an intermediary's resilience to negative shocks on its assets. The innovation of our paper is that this enhancement is connected not with bankruptcy or financial stress, but with agency costs. Our model makes the following predictions: 
(a) equity-financed intermediaries are more intensively involved than banks in monitoring the firms that they finance; (b) the bigger the difference that the intermediary's input makes, the more likely it is that the intermediary is organized as a Fund, and (c) the likelihood of Bank financing relative to Fund financing is positively correlated with the cost of monitoring and negatively correlated with the risk of the projects. The above predictions are consistent with the evidence reported by Metrick and Yasuda (2010) for private equity funds. In particular, prediction (c) implies that private equity funds are more likely than banks to finance projects with small probability of success and huge returns conditional on success, which is consistent with the evidence provided by Sahlman (1990) and Kerr, Nanda and Rhodes-Kropf (2014) for venture capital.

Our work is related to various strands of the financial economics literature. For single-project financing, Innes (1990) is the first to demonstrate the optimality of debt for providing incentives under moral hazard. Laux (2001) has demonstrated that with multiple projects cross-pledging can further enhance incentives; see also Tirole (ch.4, 2006). More generally, the optimality of debt contracts in providing incentives related to information problems has been repeatedly demonstrated in the literature; see among others, Diamond (1984), Gale and Hellwig (1985), and Gorton and Pennacchi (1990). In contrast, in this paper, by introducing uncertainty about project types into a setting similar to Holmström and Tirole (1997), we show that the optimal security that the intermediary issues to investors can be either debt or equity.

Our paper follows a well-established literature, starting with Diamond (1984), that views intermediation as a solution to the problem of delegated monitoring. ${ }^{3}$ The monitoring service that intermediaries provide in our model is similar to that in Holmström and Tirole (1997). The aim of all these papers has been to identify the advantages of bank loans over direct finance while our main concern is to compare between the solutions to the delegated monitoring problem provided with different organization structures of financial intermediation.

Lastly, our paper is also related to the fast growing theoretical literature on private equity that mainly specializes on the organizational structure of venture capital. ${ }^{4}$ Although our model is too

\footnotetext{
${ }^{3}$ Since Diamond's (1984) many other authors have analyzed the delegating monitoring problem using Townsend's (1979) costly-state verification framework; see Williamson, 1986; Krasa and Villamil, 1992; Winton, 1995; Cerasi and Daltung, 2000; Hellwig, 2000.

${ }^{4}$ As we indicated above leverage buy-outs are not directly related to this study given that they are concerned with the re-organization of firms. See Cuny and Talmor (2007) for a review of the private equity theoretical literature.
} 
abstract to account for many complex arrangements associated with these methods of finance (such as stage financing and the decision to go public that demand a dynamic framework; see Gompers, 1995), it considers private equity funds in a broader perspective by letting them compete on a level playing field against another main form of financial intermediation, namely, banks.

We organize the rest of the paper as follows. In section 2, we describe the model and in Section 3 we solve it and present the main results. In addition, we also compare them with the alternative arrangement under direct finance. In section 4, we consider the robustness of our results to (a) an increase in the number of projects thus introducing the possibility of greater diversification, and (b) a more general contracting environment, and we also discuss some empirical predictions of our model. In Section 5 we offer some concluding comments. All proofs can be found in Appendix.

\section{The Model}

The economy lasts for four dates: $0,1,2$ and 3 . It has a single good that can be stored or invested or consumed. It is populated by two entrepreneurs, E1 and E2, and many small investors. Each entrepreneur is endowed with a project that requires an investment of 1 unit of the good at date 0 . Each investor has a very small endowment of the good. Their aggregate endowment is larger than 2. The competitive net interest rate is thus equal to 0 , the net return to storage. All parties are risk neutral and protected by limited liability.

Each project can either succeed or fail. At date 3, when a project succeeds, it returns $R$, while when it fails, it returns nothing. The probability of success of a project depends on (a) a binary shock, and (b) the input of a service, which we will refer to as 'monitoring', and captures any help in management, marketing, or identifying potential consumers. Any of the investors can potentially provide the monitoring service. But as in Diamond (1984), to avoid cost replication, monitoring will be delegated to one single investor, whom we refer to as the monitor (hereafter M). The binary shock is realized at date 1 . At date 0 , it is common knowledge that the shock is identically and independently distributed across the projects. With probability $p$ a project is of type $h$, while with probability $1-p$ its type is $l$. After observing the type of a project, $\mathrm{M}$ chooses whether or not to monitor it. Monitoring does not affect the probability of success of a type $l$ project which is equal to $\underline{q}$. In contrast, for a type $h$ project, monitoring by $\mathrm{M}$ increase its probability of success from $q$ to $q$. If $\mathrm{M}$ decides not to monitor its probability of success is still $\underline{q}$. M incurs a cost $c$ when monitoring a project. Investors observe neither 
project types nor M's monitoring choice. We assume that without the monitoring service projects destroy value:

\section{Condition $1 \underline{q} R<1$.}

Entrepreneurs need to obtain funds from investors to finance their projects. There are large numbers of investors and potential monitors. Therefore, entrepreneurs have full bargaining power and the equilibrium contractual arrangement maximizes their payoff. We assume $M$ to be a financial intermediary bridging investors and the entrepreneurs, as Diamond (1984) does. Therefore, entrepreneurs issue contracts to M, who in turn issues contracts to investors. However, it might be feasible for M to provide the service only and entrepreneurs to obtain funds directly from investors. Later we will consider the advantages and disadvantages of financial intermediation relative to direct finance in this setting.

The timing of the model is as follows. At date 0, E1 and E2 sign contracts with the same monitor, M. Then, M issues securities and sells them to investors thus raising funds to finance the two projects. At date 1, M learns the types of both projects but the investors observe neither project's type. ${ }^{5}$ At date 2, M decides whether or not to monitor each project. Lastly, at date 3, each project either succeeds or fails and payments are made according to the terms of the contracts signed.

\subsection{Organization Structures of Financial Intermediation}

For the moment, we assume that a contract signed between one entrepreneur and M can depend only on the outcome of that entrepreneur's project. Later, we will consider how our results are affected when we relax this restriction by allowing for multilateral contracting between the two entrepreneurs and M. Then, given that there are only two possible outcomes, the only type of contract between one entrepreneur and $\mathrm{M}$ is one that specifies what $\mathrm{M}$ will receive when the entrepreneur's project succeeds. We are going to restrict attention to symmetric equilibria where the two entrepreneurs choose cooperatively to offer the identical contract to M. ${ }^{6}$ Thus, on the asset side of M, contracts are represented by a positive number, $m$, denoting the payment to $\mathrm{M}$ from an entrepreneur whose project has been successful. As for contracting on the liability side of M's balance sheet, given that project returns

\footnotetext{
${ }^{5}$ As entrepreneurs do not make any move after date 0 , whether or not they observe the shocks does not matter.

${ }^{6}$ The contract that each entrepreneur offers to $\mathrm{M}$ in the symmetric Nash equilibrium is identical to the contract that corresponds to our co-operative solution. Clearly, there exists a continuum of other non-symmetric Nash equilibria that we ignore in which one entrepreneur, conditional on success, pays M less and the other pays M more.
} 
are independently distributed, there are four possible states of the world. Thus, on the liability side a contract is a profile $\left\{r_{i j}\right\}$, where $i, j=1,0$ represents the success (1) or failure (0) of each project. Limited liability (LL)and symmetry imply that $r_{00}=0, r_{01}=r_{10} \equiv r_{1} \leqslant m \leqslant R$ and $r_{11}=r_{2} \leqslant 2 m .^{7}$ Following Innes (1990) we require that contracts satisfy the following payoff monotonicity condition $(\mathrm{MC})$ :

Condition $2 M C: r_{2} \geq r_{1}$.

In the absence of the constraint the optimal contract is 'live or die'. The mechanism specifies a threshold level for the income of the borrower (in our case M) such that if the income is below that level the borrower surrenders the whole income to the lender and if the income is above it the borrower keeps everything. Innes (1990) motivates the introduction of this constraint by the possibility that when the borrower's income is just below the threshold, the borrowers can pad their revenues by a small amount and thus avoid making the payment.

Definition 1 The financial intermediary is organized as a Fund $(F)$ if its liability contract is equity: $r_{2}=2 r_{1}$.

The whole equity of the fund is sold at price $2 \mathrm{~m} / \mathrm{r}_{1}$ so that investors use two units of funds to buy a fraction $r_{1} / m$ of the shares of the fund. The rest of the shares is held by M.

Definition 2 The financial intermediary is organized as a Bank (B) if its liability contract is debt: either $r_{1}=m$ and $m \leq r_{2}<2 m$ or $r_{1}=r_{2} \leq m$

The arrangement is a standard debt contract with face value $r_{2}$. When the intermediary is organized as a Bank it makes qualitative asset transformation given that the assets held by investors cannot be issued by a single entrepreneur alone.

We will demonstrate that in any equilibrium that satisfies $\mathrm{MC}$ only these two arrangements are possible.

\footnotetext{
${ }^{7}$ Limited liability of the monitor implies that $r_{1} \leq m$ and $r_{2} \leq 2 m$, while limited liability for the entrepreneurs implies that $m \leq R$.
} 


\section{Equilibrium Organization of Financial Intermediation}

The objective of the entrepreneurs is to minimize the cost of (external) finance. The first decision that the two entrepreneurs need to take is whether to offer incentives to $M$ to monitor only when the both projects are type $h$, or to incentivize her to monitor a project whenever its type is $h$ regardless the other project's type. After comparing the two cases, the entrepreneurs decide what contract to offer to M.

\subsection{Case 1: M monitors only when both projects are type $h$}

Suppose that the two entrepreneurs want $\mathrm{M}$ to monitor only when both projects are type $h$. Then, ex ante each project's probability of success is equal to $p^{2} q+\left(1-p^{2}\right) \underline{q} \equiv p_{z}$ : with probability $p^{2}$, both projects are of $h$-type and thus are monitored, and therefore succeed with probability $q$, and with probability $1-p^{2}$ at least one project is of $l$-type, so no project is monitored and the probability of success is $\underline{q}$. The two entrepreneurs choose $m$ so that (a) M has an incentive to monitor only when both projects are good, and (b) the investors' participation constraint is satisfied. Thus, the problem that the two entrepreneurs solve is as follows.

Problem 1 min $m$ subject to:

$$
\begin{aligned}
& \text { IC1: } 2 q(1-q)\left(m-r_{1}\right)+q^{2}\left(2 m-r_{2}\right)-2 c \\
& \geq \underline{q}(1-q)\left(m-r_{1}\right)+q(1-\underline{q})\left(m-r_{1}\right)+q \underline{q}\left(2 m-r_{2}\right)-c ; \\
& \text { IC2: } 2 q(1-q)\left(m-r_{1}\right)+q^{2}\left(2 m-r_{2}\right)-2 c \\
& \geq 2 \underline{q}(1-\underline{q})\left(m-r_{1}\right)+\underline{q}^{2}\left(2 m-r_{2}\right) ; \\
& \text { IC3: } 2 \underline{q}(1-\underline{q})\left(m-r_{1}\right)+\underline{q}^{2}\left(2 m-r_{2}\right) \\
& \geq \underline{q}(1-q)\left(m-r_{1}\right)+q(1-\underline{q})\left(m-r_{1}\right)+q \underline{q}\left(2 m-r_{2}\right)-c ; \\
& \text { PC1: }\left[p^{2} \cdot 2 q(1-q)+\left(1-p^{2}\right) \cdot 2 \underline{q}(1-\underline{q})\right] r_{1}+\left[p^{2} \cdot q^{2}+\left(1-p^{2}\right) \cdot \underline{q}^{2}\right] r_{2} \geq 2 ; \\
& L L: r_{1} \leq m \leqslant R \text { and } r_{2} \leq 2 m \text {; } \\
& M C: r_{2} \geq r_{1} \text {. }
\end{aligned}
$$

IC1 and IC2 are the incentive compatibility constraints that ensure that when both projects are type $h$, the monitor has an incentive to monitor both of them. On the left-hand side of both constraints we have M's expected payoff from monitoring both projects when their type is $h$. In that case, each project succeeds with probability $q$. Thus, with probability $q^{2}$ both projects succeed, M gets $2 m$ from the two entrepreneurs, and returns $r_{2}$ to investors, which implies a payoff for $\mathrm{M}$ of $2 m-r_{2}$. Furthermore, with 
probability $2 q(1-q)$, only one project succeeds and then M's payoff equals $m-r_{1}$. The right-hand side of IC1 is M's expected payoff when she only monitors one project. Then the unmonitored project succeeds with probability $\underline{q}$ while the monitored project succeeds with probability $q$. Similarly, the right-hand side of IC2 is M's payoff when she monitors neither of the projects. IC3 is the incentive compatibility constraint that ensures that if there is only one type $h$ project, $\mathrm{M}$ prefers not to monitor at all. On the left-hand side we have M's payoff when she does not monitor the type $h$ project in which case the probability of success of each project equals $\underline{q}$. On the right hand-side we have the same expression as that on the right-hand side of the weak inequality in IC1, showing M's net expected payoff when she monitors the type $h$ project. Lastly, the solution must also satisfy the participation constraint of the investors. At date 0 , with probability $p^{2}$ both projects are type $h, \mathrm{M}$ monitors both of them, and each project succeeds with probability $q$; with probability $1-p^{2}$ at least one project is type $h, \mathrm{M}$ does not monitor any project, and each project succeeds with probability $\underline{q}$. Thus, the probability that only one project succeeds is equal to $\left[p^{2} \cdot 2 q(1-q)+\left(1-p^{2}\right) \cdot 2 \underline{q}(1-\underline{q})\right]$, while the probability that both projects succeed is equal to $\tau \equiv p^{2} q^{2}+\left(1-p^{2}\right) \underline{q}^{2}$. Then, the right-hand side of PC1 shows the expected payoff of investors if $\mathrm{M}$ monitors only when both projects are type $h$, in which case she monitors both projects.

Proposition 1 Suppose that the two entrepreneurs want $M$ to monitor only when both projects are type $h$ and let $c_{\Delta} \equiv \frac{c}{q-\underline{q}}$. Then,

(i) Finance is feasible if and only if $c_{\Delta} \leq \min \left(\frac{q+\underline{q}}{\tau}\left(p_{z} R-1\right), R-\frac{2-(q+\underline{q})}{2 p_{z}-\tau}\right)$.

(ii) If finance is feasible then

(a) if $c_{\Delta} \leq \frac{q+\underline{q}}{2 p_{z}-\tau}$ the optimal contract is given by

$$
\begin{aligned}
& r_{1}=m=\frac{1}{p_{z}}+\frac{\tau}{p_{z}(q+\underline{q})} c_{\Delta} ; \\
& r_{2}=\frac{2}{p_{z}}-\frac{2 c_{\Delta}}{q+\underline{q}} \frac{p_{z}-\tau}{p_{z}} \geq r_{1},
\end{aligned}
$$

(b) if $c_{\Delta}>\frac{q+q}{2 p_{z}-\tau}$ the optimal contract is given by

$$
\begin{aligned}
& r_{2}=r_{1}=\frac{2}{2 p_{z}-\tau} ; \\
& m=c_{\Delta}+\frac{2-(q+\underline{q})}{2 p_{z}-\tau}>r_{1} .
\end{aligned}
$$

As the liability contract of $M$ is debt with face value $r_{2}, M$ is organized as a Bank.

Proof. See the Appendix. 
We can gain a better intuition of the result by temporarily ignoring the monotonicity constraint (MC). In this case when the two entrepreneurs would like M to monitor only when both projects are type $h$, we show that IC3 is never binding - that is, disincentivizing M to monitor if only one project is type $h$ is not the issue. The issue is to incentivize $\mathrm{M}$ to monitor the two projects (rather than either only one or none) when both projects are type $h$. The same incentive problems would arise if there were no type shock, that is, if the projects were always type $h$. Then, as Laux (2001) shows (and see also Tirole, 2006, p.159), the least costly way of giving M incentives to monitor is to let M get paid only when both projects succeed. In our setting, where $\mathrm{M}$ is the financial intermediary, to deprive $\mathrm{M}$ of any net payment in the case where only one project succeeds, $r_{1}$ is set equal to $m$. Then, $r_{2}$ is pinned down by the investors' participation constraint. If $m$, and thus $r_{1}$, is large then $r_{2}$ can be very small, even nil. This type of contract, especially if $r_{2}=0$, is called 'live or die' and was originally derived by Innes $(1990) .^{8}$

The payment to $\mathrm{M}$ (i.e. $m$ ) increases with $c_{\Delta}$, which measures the cost of incentivizing him. The above argument implies that with the optimal scheme, $r_{1}$ increases with $c_{\Delta}$ and $r_{2}$ decreases with it. Therefore, there will be a threshold level for $c_{\Delta}$, which, according to Proposition 1 , is $\frac{q+\underline{q}}{2 p_{z}-\tau}$, at which $r_{1}=r_{2}$. If $c_{\Delta}$ is below it then $r_{1} \leq r_{2}$ and $\mathrm{MC}$ is not binding. This is the case described by part (a). In this case, the optimal scheme of Laux (2001) is exactly implemented by setting $r_{1}=m$.

If $c_{\Delta}$ is above the threshold, then with the above scheme we would have $r_{1}>r_{2}$, and therefore MC will be binding. This is the case described by part (b). MC forces $r_{1}$ to go down and equal $r_{2}$ and thus induces $r_{1}<m$. That is, the monitor gets payoff $m-r_{1}$ in the event of one success. Thus, with the distortion of MC, the optimal scheme of Laux (2001) cannot be exactly implemented in this case. Note, however, that even without MC, that scheme will not always be exactly implemented, because with $r_{2}$ keep decreasing as $c_{\Delta}$ increases, at some point $r_{2}=0$ and the limited liability constraint for the investors will begin to bind. This will distort the mechanism in the same way as MC.

Figure 1 shows the optimal contract in the $\left(c_{\Delta}, R\right)$ plane, where $\alpha_{B} \equiv \frac{2-(q+\underline{q})}{2 p_{z}-\tau}$ :

\footnotetext{
${ }^{8}$ See also Tirole (p.133, 2006).
} 


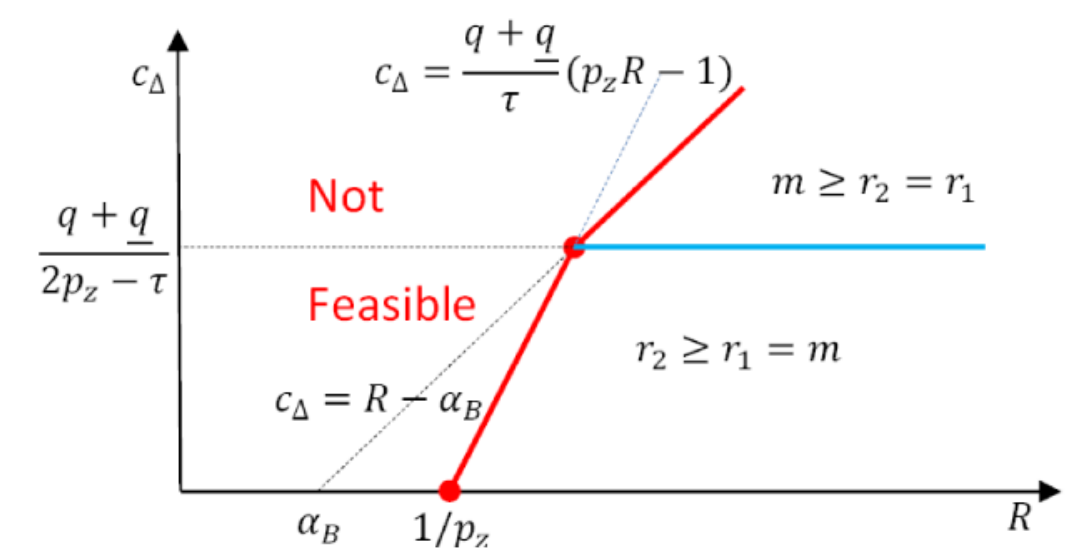

Figure 1: The optimal contract if M is incentivized to monitor only when both projects are type $h$

To the left of the kinked bold line the combinations of low project returns $R$ and high agency costs $c_{\Delta}$ imply that finance is not feasible. The kink is there because for sufficiently high agency costs, the contract design is further restricted by MC. Notice that even if monitoring costs are equal to zero unless $R \geqslant \frac{1}{p_{z}}$ investors cannot break even.

\subsection{Case 2: $M$ monitors a project whenever it is type $h$}

Now, consider the case when the two entrepreneurs would like $\mathrm{M}$ to monitor a project whenever it is type $h$. In this case, each project's ex ante success possibility is equal to $p_{s} \equiv p q+(1-p) \underline{q}$. Now, they solve the following problem:

Problem $2 \min m$ subject to:

$$
\begin{aligned}
& \text { IC1; IC2; } \\
& \text { IC4: } \underline{q}(1-q)\left(m-r_{1}\right)+q(1-\underline{q})\left(m-r_{1}\right)+q \underline{q}\left(2 m-r_{2}\right)-c \\
& \geq 2 \underline{q}(1-\underline{q})\left(m-r_{1}\right)+\underline{q}^{2}\left(2 m-r_{2}\right) ; \\
& \text { PC2: } 2 p_{s}\left(1-p_{s}\right) \cdot r_{1}+p_{s}^{2} \cdot r_{2} \geq 2 \text {; } \\
& L L: r_{1} \leq m \leqslant R \text { and } r_{2} \leq 2 m \text {; } \\
& M C: r_{2} \geq r_{1} \text {. }
\end{aligned}
$$

The incentive compatibility constraints IC1 and IC2 are common to both problems, given that once more the two entrepreneurs would like M to monitor both projects when both are type $h$. However, in 
this new problem when one project is type $h$, the other type $l$, the two entrepreneurs want M to monitor the type $h$ one. Therefore, IC4 is obtained from IC3 by reversing the direction of the weak inequality. The participation constraint is also similar to that of Problem 1; the only difference is that a project's ex ante probability of success is now higher $\left(p_{s}>p_{z}\right)$.

The following proposition characterizes the optimal contract for this case.

Proposition 2 Suppose that the two entrepreneurs would like $M$ to monitor every type $h$ project and let $c_{\Delta} \equiv \frac{c}{q-\underline{q}}$. Then,

(i) If $q / \underline{q}<(1+p) / p$, then finance is feasible if and only if $c_{\Delta} \leq \min \left(\frac{2 q}{p_{s}}\left(R-\frac{1}{p_{s}}\right), R-\frac{2(1-q)}{2 p_{s}-p_{s}^{2}}\right)$. If finance is feasible then $M$ is organized as a Bank.

(ii) If $q / \underline{q} \geq(1+p) / p$, then finance is feasible if and only if $c_{\Delta} \leq R-\frac{1}{p_{s}}$. If finance is feasible the optimal contract is given by

$$
\begin{aligned}
r_{1} & =\frac{r_{2}}{2}=\frac{1}{p_{s}} \\
m^{S} & =c_{\Delta}+\frac{1}{p_{s}} .
\end{aligned}
$$

As the liability contract of $M$ is equity, $M$ is organized as a Fund.

Proof. See the Appendix.

When $q / \underline{q}<(1+p) / p$, which is case (i), the results are very similar as those of Proposition 1 . The shape of the contracts is driven by the benefit of cross-pledging, which demands that $\mathrm{M}$ should be paid only in the event that both projects succeed. Different to the preceding case, however, if $q / \underline{q}$ increases beyond the threshold $(1+p) / p$, we have a switch in the liability contract from debt to equity. The intuition is as follows. In the present case the entrepreneurs want $\mathrm{M}$ to monitor an $h$-type project even if the other project is a $l$-type, which succeeds with probability $\underline{q}$. In order for $\mathrm{M}$ to do so, part of the incentives should come from the payment to her at the contingency where only one project succeeds, which is more likely to happen if $\underline{q}$ is lower. Thus, the lower is $\underline{q}$, the greater the part that this payment plays. For example, if $\underline{q}=0$, namely, if the $l$-type project never has a chance to succeed, $M$ has an incentive to monitor the other $h$-type project only if she receives a payment no less than $c_{\Delta}$ in the event when only one project succeeds, i.e. $m-r_{1} \geq c_{\Delta}$. This consideration requires a low value for $r_{1}$, in contrast to what is required for cross-pledging, that is a high value of $r_{1}$. The balance of these two forces gives us the equity contract at the optimum if $\underline{q}$ is low enough, that is, $\underline{q} \leq q p /(1+p)$. If $\underline{q}$ is 
beyond this threshold, the benefit of cross-pledging still dominates, commanding that the the liability contract is debt and M is organized as Bank, which is case (i).

In contrast, there is no such switch in the preceding case, where the entrepreneurs want M to monitor an $h$-type project only if the other one is also an $h$-type, and will thus succeed with the relatively higher probability, $q$. Hence the concern that drives the equity contract does not arise.

\subsection{Equilibrium Organization Structure}

The equilibrium structure of financial intermediation is decided by the two entrepreneurs since they have all the bargaining power. For $q / \underline{q}<(1+p) / p$ the optimal intermediation structure, if finance is feasible, is always Bank. If $q / \underline{q}>(1+p) / p$, Propositions 1 and 2 show that the optimal structure is Bank if $\mathrm{M}$ is incentivized to monitor only when both projects are type $h$, which is case 1 above; and it is Fund if $\mathrm{M}$ is incentivized to monitor a project so long as it is type $h$, which is case 2 above. Comparing the entrepreneurs' payoff between these two cases leads to the following result.

Theorem 1 Equilibrium organization structure:

(i) Suppose that $q / \underline{q} \leqslant(1+p) / p$. If finance is feasible, the equilibrium structure is Bank.

(ii) Suppose that $q / \underline{q}>(1+p) / p$. Then,

(a) if $c_{\Delta} \geqslant \min \left(\frac{q+\underline{q}}{\tau}\left(p_{z} R-1\right), R-\frac{2-(q+q)}{2 p_{z}-\tau},\right)$ and $c_{\Delta} \geqslant R-\frac{1}{p_{s}}$ finance is not feasible,

(b) if $\min \left(\frac{q+\underline{q}}{\tau}\left(p_{z} R-1\right), R-\frac{2-(q+\underline{q})}{2 p_{z}-\tau},\right) \leqslant c_{\Delta}<R-\frac{1}{p_{s}}$, the only feasible structure is Fund,

(c) if $R-\frac{1}{p_{s}} \leqslant c_{\Delta}<\min \left(\frac{q+\underline{q}}{\tau}\left(p_{z} R-1\right), R-\frac{2-(q+\underline{q})}{2 p_{z}-\tau}\right)$, the only feasible structure is Bank,

(d) if $c_{\Delta}<\min \left(\frac{q+q}{\tau}\left(p_{z} R-1\right), R-\frac{2-(q+\underline{q})}{2 p_{z}-\tau}, R-\frac{1}{p_{s}}\right)$, both structures are feasible, and

Bank dominates Fund if

$$
\min \left(\frac{\left(p_{s}-p_{z}\right)(q+\underline{q})+q \underline{q}}{\left(p_{s}-p_{z}\right)(q+\underline{q})} c_{\Delta}, c_{\Delta}+\frac{q \underline{q}}{\left(p_{s}-p_{z}\right)\left(2 p_{z}-\tau\right)}\right)>R
$$

otherwise, Fund dominates Bank.

Proof. See the Appendix.

Corollary 1 If $q / \underline{q}>(1+p) / p$ and $q \underline{q}<\left(p_{s}-p_{z}\right)[2-(q+\underline{q})]$, the equilibrium structure is Fund so long as finance is feasible.

Proof. See the Appendix. 
For given $p$, Figure 2 below illustrates how the equilibrium structure of financial intermediation (conditional on the feasibility of finance) depends on $(q, \underline{q})$.

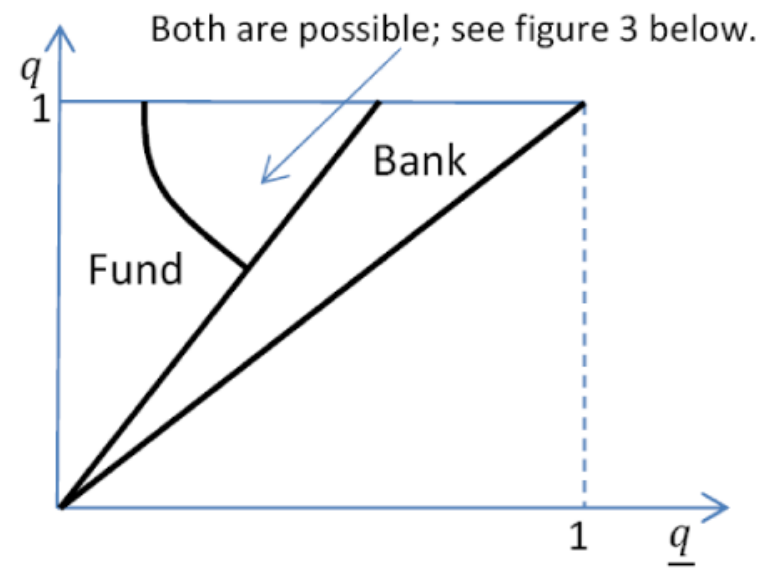

Figure 2: Equilibrium structure on the $q-\underline{q}$ plane

Figure 3 illustrates the equilibrium structure on the $c_{\Delta}-R$ plane for the case in which $q \underline{q}>$ $\left(p_{s}-p_{z}\right)[2-(q+\underline{q})]$ and $q / \underline{q}>(1+p) / p$, namely, both Fund and Bank can arise in equilibrium.

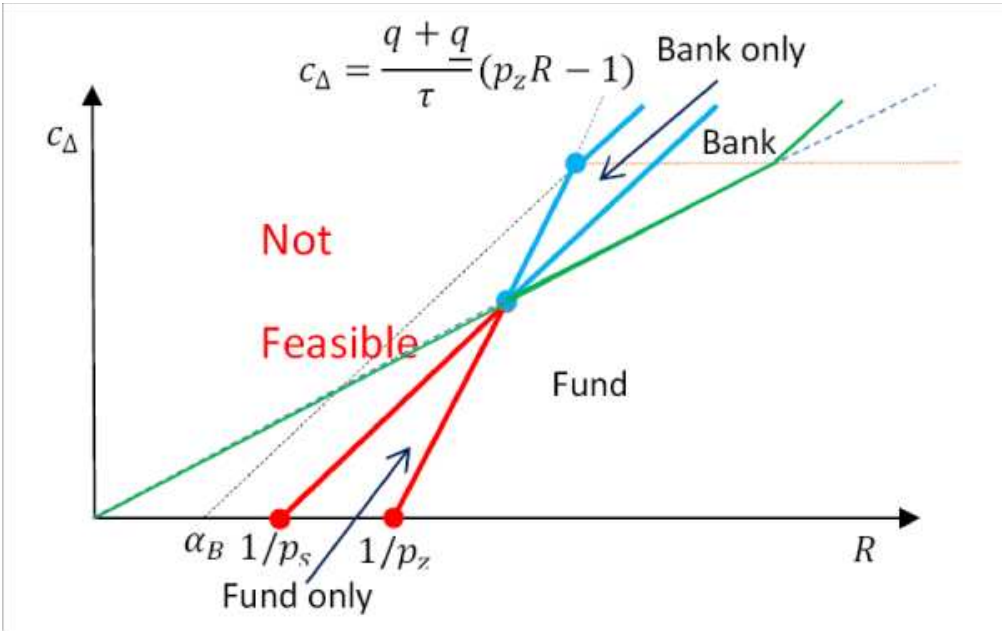

Figure 3: The equilibrium structure when both Fund and Bank can arise in equilibrium 
Here is the intuition behind the trade-off between the two organization structures. The cost of providing incentives to $\mathrm{M}$ is lower under Bank. The optimality of debt contracts in the presence of moral hazard is well known in the literature (e.g. Innes,1990; Laux, 2001; Tirole, 2006). This is a consequence of the 'maximum incentive principle', which says that the agent shall receive a positive payment only when all the informative signals display the values indicating that the agent has chosen high effort. ${ }^{9}$ Therefore, M should receive a payoff only when both projects succeed. By introducing uncertainty about the project's type this paper finds a disadvantage of debt contracts. The very feature that enables them to provide incentives at a lower cost makes them less robust to bad news. To see this, consider the extreme case where $\underline{q}=0$. In this case, according to the corollary the equilibrium structure is Fund. Suppose that only one project is type $h$. Under the Bank structure, as there is at most one successful project, M's payoff is always 0, even if she monitors the type $h$ project. Thus, she has no incentives to monitor at all. Put differently, one piece of bad news is sufficient to destroy all M's incentives to monitor. In contrast, under the Fund structure M has the incentive to monitor the only type $h$ project because she receives a share of the output. We conclude that while it is cheaper to provide incentives by opting for the Bank structure, the alternative Fund structure is more robust to the realization of negative shocks on the asset side. While the view that the advantage of equity is to make firms in general more robust to negative shocks is commonly held, it is usually justified with reducing costs associated with bankruptcy or financial stress. In contrast, in this paper, where such costs are absent, the benefits of equity are associated with agency costs.

Table 1 provides numerical examples for cases (2b), (2c) and (2d-last two columns) of Theorem 1, where the parameters in the last three lines are endogenous.

\footnotetext{
${ }^{9}$ See Laffont and Martimont (2003) and Bolton and Dwatripont (2005).
} 
Table 1: Equilibrium Contracts

$\begin{array}{rrrrr}\text { Feasibility } & \text { Bank } & \text { Fund } & \text { Both } & \text { Both } \\ \text { Equilibrium } & \text { Bank } & \text { Fund } & \text { Bank } & \text { Fund } \\ R & 2 & 2 & 2 & 2 \\ p & 0.9 & 0.6 & 0.9 & 0.9 \\ q & 0.8 & 0.8 & 0.8 & 0.7 \\ \underline{q} & 0.2 & 0.2 & 0.2 & 0.2 \\ c & 0.4 & 0.1 & 0.25 & 0.1 \\ r_{1} & 1.9689 & 1.78571 & 1.77721 & 1.53846 \\ r_{2} & 2.60477 & 3.57143 & 2.72109 & 3.07692 \\ m & 1.9689 & 1.95238 & 1.77721 & 1.73846\end{array}$

\subsection{Intermediate versus Direct Finance}

Thus far, we have assumed that $\mathrm{M}$ is a financial intermediary that both provides the monitoring service and passes funds from investors to entrepreneurs. But is it possible that an arrangement of direct finance, where $\mathrm{M}$ only provides the monitoring service, can do better? Below we show that this is never the case and moreover if contracts between one entrepreneur and $\mathrm{M}$ are restricted to be bilateral (as we have assumed thus far), direct finance is dominated by financial intermediation in some cases.

Proposition 3 Suppose that the contract between an entrepreneur and $M$ can only be conditioned on the outcome of that entrepreneur's project. Then under the optimal arrangement of direct finance, $M$ monitors a project whenever it is type $h$. This allocation can be implemented under the Fund arrangement of financial intermediation.

Proof. See the Appendix.

With bilateral contracts under direct finance the monitor's net payoff is 0 when both projects fail, $m^{d}$ when only one project succeeds and $2 m^{d}$ when both projects succeed. This compensation structure generates incentives to monitor if $m^{d} \geq c_{\Delta}$, in which case $\mathrm{M}$ monitors a project whenever it is of type $h$. Thus, under the optimal arrangement of direct finance each entrepreneur hires a monitor (not necessarily the same) for the monitoring service at a wage $c_{\Delta}$ and issues directly to investors a security that promises a repayment of $1 / p_{s}$. Clearly, this allocation is implemented under Fund. Moreover, Fund has two advantages over the arrangement of direct finance. Firstly, under direct finance, investors 
would be vulnerable to the possibility that the entrepreneur terminates the contract with the monitor after being financed. In contrast, under financial intermediation, the monitoring service is bundled with financing and this possibility cannot arise. This is because while a firm can find an excuse to fire an employee or a contract partner, it cannot fire a creditor before it clears its debt obligations to him. Secondly, the arrangement of financial intermediation is associated with a certain economy of scale. Investors will not commit their funds unless they are convinced that entrepreneurs will be monitored. Under direct finance this can be achieved only if investors oversee all the entrepreneurs individually to ensure that they are monitored. Put differently, they depend on the governance structure of each and every entrepreneur's firm. In contrast, under financial intermediation, investors rely on the governance structure of only one firm, namely, the intermediary.

As Proposition 3 suggests that the best arrangement under direct finance implements only the allocation that Fund implements under financial intermediation, the following result is straightforward.

Corollary 2 Under parameter values where according to Theorem 1, Bank dominates Fund, financial intermediation dominates direct finance.

The advantage of the Bank structure is its ability to perform asset transformation. The only way to implement the Bank solution under direct finance is by using multilateral mechanisms that allow for the contracts between one entrepreneur and $\mathrm{M}$ to be contingent on the outcome of the other entrepreneur's project. This imposes a stronger requirement of information on the entrepreneurs. What happens with multi-lateral contracting is discussed below.

\section{Discussion}

In this section we (a) examine the implications of diversification for the choice of intermediation structure, (b) consider the robustness of our solutions to multilateral contracting between entrepreneurs and $\mathrm{M}$, and (c) discuss the empirical relevance of our model.

\subsection{Diversification and Internal Control}

Up to this point, we have assumed that there are only two entrepreneurs. What happens if the financial intermediary M can fully diversify its assets as the number of the entrepreneurs goes to infinity? Full diversification offers the Bank structure some advantages because (a) under the Bank structure M's 
profits are zero while under the Fund structure M earns positive profits, and (b) there is no aggregate uncertainty about the portfolio quality which cancels the robustness advantage that Fund has. However, the possibility of full diversification does not destroy the trade-off between the two structures considered above, if we take into account the internal control problems that are usually associated with large enterprises. In our analysis above, the problem is assumed away given that $\mathrm{M}$ is able to monitor the two projects by herself. When there are large number of projects, $\mathrm{M}$ would need to delegate the monitoring activities to others. Given that monitoring is not observable by third parties, $\mathrm{M}$ faces the problem of monitoring these delegates. Define as "internal control cost" the cost incurred by M to ensure that a delegate will monitor the assigned project. The following proposition makes clear that the Bank structure suffers more from internal control problems than the Fund structure does.

Proposition 4 If each monitor can only monitor one project and the internal control cost is no smaller than $c$, then the only equilibrium structure is Fund.

Proof. See the Appendix.

The reason that Bank suffers more serious internal control problems is rooted in the very feature that enables it to save on incentive costs. Under the Bank structure, each monitor imposes some negative externality, or "cross pledging" according to Tirole (2006), upon other monitors given that failure to monitor on his part reduces the expected income of all monitors. It is exactly because of this externality that Bank saves on incentive costs relative to Fund. Thus, if each monitor's behavior is not controlled to internalize the externality, cross pledging would not work and the Bank structure would collapse. In contrast, the Fund does not incur the internal control cost because of its lack of "cross pledging". Under Fund, each monitor is incentivized by obtaining a positive share of the output from the project she monitors, independent of the outcomes of the other projects.

Thus, our main conclusions about the trade-off between the two main structures of financial intermediation is robust to the possibility of full diversification so long as the internal control problems limit the Bank's capacity for diversification.

\subsection{Multilateral Contracting}

One restriction that we have imposed on contract design is that each entrepreneur can condition the terms of his contract with $\mathrm{M}$ only on the outcome of his own project. This seems to be reasonable 
given the potential high costs of information gathering associated with conditioning the terms of each contract on the outcomes of other projects. In any case, the following proposition demonstrates that allowing multilateral contracts does not make improvement as long as the cost of monitoring is not too high.

Proposition 5 As longs as $c_{\Delta} \leqslant \min \left(\frac{q+\underline{q}}{2 p_{z}-\tau}, \frac{2 q}{p_{s}\left(2-p_{s}\right)}\right)$, allowing for multilateral contracting does not change the equilibrium allocation.

Proof. See the Appendix.

The intuition behind the proposition is that allowing for multilateral contracting makes a difference only if the optimal arrangement features "cross pledging", in which case the payment to M from one successful entrepreneur depends on the outcome of the other entrepreneur. Therefore, multilateral contracting can make improvement only in circumstances where Bank is the optimal structure. By the discussion of Proposition 1, if $c_{\Delta}$ is not too high - that is, below the $\frac{q+q}{2 p_{z}-\tau}-$ the optimal level of cross pledging has been exactly implemented under Bank with bilateral contracting, through Bank's ability to perform asset transformation; the same happens if $c_{\Delta} \leqslant \frac{2 q}{p_{s}\left(2-p_{s}\right)}$ for the case of Proposition 2(i). If $c_{\Delta}$ goes higher, the implementation of the optimal cross pledging is distorted by the binding MC. Thus, multilateral contracting makes a difference. However, even if the MC was absent, the distortion would still arise if $c_{\Delta}$ is high enough, due to the binding limited liability constraint $r_{2} \geq 0$.

\subsection{Empirical Predictions}

Our model yields a number of empirical predictions about (a) the capacity of each organization structure to raise pledgeable income, (b) the relationship between firm's characteristics and the structure of the intermediary that finances it, and (c) the operations of the two organization structures.

Prediction 1 Keeping profitability $(R)$ constant Bank is more likely to dominate when the monitoring cost $(c)$ are higher and the payoff to monitoring $(q-\underline{q})$ is lower.

The payoff to monitoring can be measured by the difference $q-\underline{q}$, because this is the difference in the probability of success that monitoring makes to a type $h$ project. Clearly, if the difference declines the payoff to monitoring declines too. Then the prediction follows directly from Theorem 1 (see also Figures 2 and 3) by noticing that $c_{\Delta}$ is increasing in the size of the monitoring cost $c$ and decreasing 
in $q-\underline{q}$ and that the higher is $c_{\Delta}$, the more likely Bank dominates Fund and becomes the equilibrium structure.

Prediction 2 Keeping monitoring costs and the payoff to monitoring constant Fund is more likely when profitability is high.

With profitability measured by $R$, the prediction follows directly from Figure 3.

These two predictions together may suggest that Bank is more likely to be associated with mature firms, Fund with firms in high-tech innovative sectors or start-up firms. This is because low $q-\underline{q}$ and low $R$, according to evidence provided by Dunne, Roberts and Samuelson (1988), are the characteristics of mature firms. In contrast, according to Sahlman (1990) the profitability of young firms in high-risk innovative sectors is very strong conditional on survival (namely success), and also these are the firms more likely to be financed by venture capitalists.

Prediction 3 Fund structured intermediaries monitor more intensively than Bank structured intermediaries.

This prediction is an immediate consequence of Propositions 1 and 2. If Fund is the equilibrium structure the intermediary always monitors a type $h$ project, that is, monitoring happens in three contingencies regarding the profile of the entrepreneurs' types: $(h, h),(l, h)$ and $(h, l)$. In contrast, if Bank is the equilibrium structure, it may be the case that monitoring occurs only in the contingency of $(h, h)$. Therefore, monitoring, which in our model can be of any service that improves the chance of success to the project, occurs in more contingencies under Fund than it does under Bank. Indeed, as Gompers (1995) and Sahlman (1990) observe, private equity funds, especially venture capitalists, are much more active than banks in partaking the decision-making of the firms that they finance.

\section{Conclusion}

Financial intermediaries channel trillions of funds from investors to entrepreneurs providing various services to their customers. There is a lot of progress made in understanding their advantages over direct finance. However, there are still questions about them that are not very well understood. Among them is the question: what determines their organization structure? In particular, what are the advantages or disadvantages of banks over private equity funds? This paper considers this problem from a perspective 
of agency costs associated with incentivizing the intermediary to provide valuable services. Using a mechanism design approach, we find the optimal contractual arrangement that provides incentives to the intermediary to monitor its clients. Based on the nature of its liability side contract, the arrangement takes one of two forms, namely, Bank or Fund. The trade-off between the two structures is that it is cheaper to offer incentives using the Bank option, but the Fund alternative is more robust to the arrival of bad news about the quality of assets. This robustness is connected not with the considerations of bankruptcy or financial stress, but with agency problems of the intermediaries. In general, we demonstrate that agency costs can be one useful perspective - there are many others - to investigate the organization of financial intermediaries.

The simplicity of the model triggers the question about the theory's robustness and relevance. We show that direct finance can never dominate financial intermediation, but the inverse holds in some cases. We also demonstrate that our results are robust to generalizing the contracting environment and to increasing the number of projects. In particular, we argue that in connection with greater diversification, banks may suffer a more serious internal-control problem relative to private equity funds. Lastly, we argued that our model delivers predictions consistent with empirical observations, such as relative to banks, private equity funds are more involved in the running of the firms that they finance, contribute more to the success of these firms, and provide funds to higher-risk, higher-return firms

\section{Appendix}

\section{Proof of Proposition 1}

Let $m^{Z}$ denote the optimal symmetric solution for $m$. Constraint IC1 can be written as:

$$
\begin{aligned}
& \left(m^{Z}-r_{1}\right)(2 q(1-q)-\underline{q}(1-q)-q(1-\underline{q}))+\left(2 m^{Z}-r_{2}\right)\left(q^{2}-q \underline{q}\right) \geq c \Longleftrightarrow \\
& \left(m^{Z}-r_{1}\right)(q-\underline{q})(1-2 q)+\left(2 m^{Z}-r_{2}\right) q(q-\underline{q}) \geq c \Longleftrightarrow \\
& m^{Z}-\left((1-2 q) r_{1}+q r_{2}\right) \geq c_{\Delta} .
\end{aligned}
$$

IC2 can be written as: 


$$
\begin{aligned}
& 2\left(m^{Z}-r_{1}\right)(q(1-q)-\underline{q}(1-\underline{q}))+\left(2 m^{Z}-r_{2}\right)\left(q^{2}-\underline{q}^{2}\right) \geq 2 c \Longleftrightarrow \\
& 2\left(m^{Z}-r_{1}\right)(1-q-\underline{q})(q-\underline{q})+\left(2 m^{Z}-r_{2}\right)(q+\underline{q})(q-\underline{q}) \geq 2 c \Longleftrightarrow \\
& m^{Z}-\left((1-q-\underline{q}) r_{1}+\frac{q+\underline{q}}{2} r_{2}\right) \geq c_{\Delta} .
\end{aligned}
$$

PC1 can be written as:

$$
\left[p^{2} q(1-q)+\left(1-p^{2}\right) \underline{q}(1-\underline{q})\right] 2 r_{1}+\left[p^{2} q^{2}+\left(1-p^{2}\right) \underline{q}^{2}\right] r_{2} \geq 2 .
$$

We can then write Problem 1 as:

$$
\begin{aligned}
& \min _{m^{Z}, r_{1}, r_{2}} m^{Z} \text {, s.t.(A1), (A2), IC3 and (A3); and } \\
& 0 \leq r_{1} \leq m^{Z} \leq R, 0 \leq r_{2} \leq 2 m^{Z} .
\end{aligned}
$$

We prove the following results:

Lemma 1 If IC2 (i.e. A2) is binding then IC3 is not binding.

Proof. For $i=1,2,3$, denote by $L_{i}$ the left hand side (LHS) of IC $i$, by $R_{i}$ the right hand side (RHS); then IC $i$ is $L_{i} \geq R_{i}$. Note that $L_{1}=L_{2} ; R_{2}=L_{3}$; and $R_{1}=R_{3}$. Therefore, if IC2 is binding, that is if $L_{2}=R_{2}$, then that $L_{1} \geq R_{1}$ implies that $L_{3} \geq R_{3}$ - thus IC1 implies IC3 - because $L_{3}=R_{2}=L_{2}=L_{1} \geq R_{1}=R_{3}$. Therefore, IC3 is not binding. QED

\section{Lemma 2 (A2) is binding.}

Proof. First, notice that minimization of $m^{Z}$ implies that either (A1) or (A2) must be binding. Second, notice that (A2) implies (A1) if and only if

$$
\begin{aligned}
(1-q-\underline{q}) r_{1}+\frac{q+\underline{q}}{2} r_{2} \geq & (1-2 q) r_{1}+q r_{2} \Longleftrightarrow(q-\underline{q}) r_{1} \geq \frac{q-\underline{q}}{2} r_{2} \Longleftrightarrow \\
& r_{1} \geq \frac{r_{2}}{2} .
\end{aligned}
$$

And vice versa. Thus, if (A1) is binding, contrary to the lemma, then $r_{1} \leq \frac{r_{2}}{2}$. In this case, $m^{Z}=$ $\left((1-2 q) r_{1}+q r_{2}\right)+c_{\Delta}$. To minimize $m^{Z}$ the two entrepreneurs solve:

$$
\begin{aligned}
\min H^{1} & =(1-2 q) r_{1}+q r_{2} \text { subject to (A3) and } \\
0 & \leq r_{1} \leq m^{Z} \leqslant R, 0 \leq r_{2} \leq 2 m^{Z} .
\end{aligned}
$$


Certainly (A3), the IR constraint of the investors, is binding and it follows that $d r_{2}=-\frac{2\left[p^{2} q(1-q)+\left(1-p^{2}\right) \underline{q(1-q)]}\right.}{p^{2} q^{2}+\left(1-p^{2}\right) \underline{q}^{2}} d r_{1}$. Then,

$$
d H^{1}=\left[(1-2 q)-q \frac{2\left[p^{2} q(1-q)+\left(1-p^{2}\right) \underline{q}(1-\underline{q})\right]}{p^{2} q^{2}+\left(1-p^{2}\right) \underline{q}^{2}}\right] d r_{1} .
$$

The expression in the square brackets is negative:

$$
\begin{aligned}
& 1-2 q<q \frac{2\left[p^{2} q(1-q)+\left(1-p^{2}\right) \underline{q}(1-\underline{q})\right]}{p^{2} q^{2}+\left(1-p^{2}\right) \underline{q}^{2}} \Longleftrightarrow \\
& p^{2} q^{2}+\left(1-p^{2}\right) \underline{q}^{2}<2 q\left(p^{2} q^{2}+\left(1-p^{2}\right) \underline{q}^{2}+p^{2} q(1-q)+\left(1-p^{2}\right) \underline{q}(1-\underline{q})\right) \Longleftrightarrow \\
& p^{2} q^{2}+\left(1-p^{2}\right) \underline{q}^{2}<2 q\left(p^{2} q+\left(1-p^{2}\right) \underline{q}\right)
\end{aligned}
$$

where given that $q>\underline{q}$ the last inequality clearly holds. Thus $\frac{d H^{1}}{d r_{1}}<0$ and the solution for this case is to set $r_{1}=\frac{r_{2}}{2}$, which implies that the overall optimal solution for Problem 1 is in the region $r_{1} \geq \frac{r_{2}}{2}$, that is, (A2) is binding. QED

With (A2) binding, $m^{Z}=(1-q-\underline{q}) r_{1}+\frac{q+\underline{q}}{2} r_{2}+c_{\Delta}$. Then, the problem of the two entrepreneurs to minimize $m^{Z}$ becomes:

$$
\begin{aligned}
\min H^{2} & =(1-q-\underline{q}) r_{1}+\frac{q+\underline{q}}{2} r_{2} \text { subject to (A3) and } \\
0 & \leq r_{1} \leq m^{Z} \leqslant R, 0 \leq r_{2} \leq 2 m^{Z}
\end{aligned}
$$

and the limited liability constraints become:

$$
\begin{aligned}
& 0 \leq r_{1} \leq(1-q-\underline{q}) r_{1}+\frac{q+\underline{q}}{2} r_{2}+c_{\Delta} \\
& 0 \leq r_{2} \leq 2(1-q-\underline{q}) r_{1}+(q+\underline{q}) r_{2}+2 c_{\Delta} .
\end{aligned}
$$

Lemma 3 (a) If $c_{\Delta} \leq \frac{q+\underline{q}}{2 p_{z}-\tau}$ then $r_{1}=\frac{1}{p_{z}}+\frac{\tau}{p_{z}(q+\underline{q})} c_{\Delta}, r_{2}=\frac{2}{p_{z}}\left(1-\frac{p_{z}-\tau}{q+\underline{q}} c_{\Delta}\right), m^{Z}=r_{1}$, and

(b) if $c_{\Delta} \geq \frac{q+\underline{q}}{2 p_{z}-\tau}$ then $r_{1}=r_{2}=\frac{2}{2 p_{z}-\tau}, m^{Z}=\frac{2-q-\underline{q}}{2 p_{z}-\tau}+c_{\Delta}$.

Proof. Once more the binding (A3) implies that $d r_{2}=-\frac{2\left[p^{2} q(1-q)+\left(1-p^{2}\right) \underline{q}(1-\underline{q})\right]}{p^{2} q^{2}+\left(1-p^{2}\right) \underline{q}^{2}} d r_{1}$. Then, $d H^{2}=$ $(1-q-\underline{q}) d r_{1}+\frac{q+\underline{q}}{2} d r_{2}=\left[(1-q-\underline{q})-\frac{q+\underline{q}}{2} \times \frac{2\left[p^{2} q(1-q)+\left(1-p^{2}\right) \underline{q}(1-\underline{q})\right]}{p^{2} q^{2}+\left(1-p^{2}\right) \underline{q}^{2}}\right] d r_{1}$. Next, we show that the expression in the square brackets is negative.

$$
\begin{aligned}
& 1-q-\underline{q}<\frac{q+\underline{q}}{2} \times \frac{2\left[p^{2} q(1-q)+\left(1-p^{2}\right) \underline{q}(1-\underline{q})\right]}{p^{2} q^{2}+\left(1-p^{2}\right) \underline{q}^{2}} \Longleftrightarrow \\
& p^{2} q^{2}+\left(1-p^{2}\right) \underline{q}^{2}-(q+\underline{q})\left[p^{2} q^{2}+\left(1-p^{2}\right) \underline{q}^{2}\right]<(q+\underline{q})\left[p^{2} q(1-q)+\left(1-p^{2}\right) \underline{q}(1-\underline{q})\right] \Longleftrightarrow \\
& p^{2} q^{2}+\left(1-p^{2}\right) \underline{q}^{2}<(q+\underline{q})\left(p^{2} q+\left(1-p^{2}\right) \underline{q}\right) \Longleftrightarrow-q \underline{q}<0 .
\end{aligned}
$$


Thus $\frac{d H^{2}}{d r_{1}}<0$, which implies the entrepreneurs must set $r_{1}$ as high as possible. Therefore, the second inequality of (A4) is binding given that from the binding (A3) we know that $r_{1}$ and $r_{2}$ are negatively related. From the binding second inequality of (A4) and the binding (A3) we get the values of $r_{1}$ and $r_{2}$ which is the solution for the case when $c_{\Delta} \leq \frac{q+q}{2 p_{z}-\tau}$, that is when MC is satisfied. Part (b) of the lemma shows the solution when MC is violated. To obtain the solution for part set $r_{2}=r_{1}$ and then use (A3). QED

Therefore, as long as finance is feasible, that is, the limited liability constraint of the two entrepreneurs is satisfied, the solution given in Lemma 3 is the solution to Problem 1. Now we are left to check the feasibility of finance, namely, that the constraint $m^{Z} \leq R$ is satisfied. Let $T_{1} \equiv \frac{q+\underline{q}}{2 p_{z}-\tau}$, $T_{2} \equiv \frac{q+\underline{q}}{\tau}\left(p_{z} R-1\right)$ and $T_{3} \equiv R-\frac{2-q-q}{2 p_{z}-\tau}$. Then we have the following result:

Lemma 4 Finance is feasible if and only if $c_{\Delta} \leq \min \left(T_{2}, T_{3}\right)$.

Proof. If $c_{\Delta} \leq T_{1}$, that is MC is nonbinding, then from Lemma 3 we have $m^{Z}=\frac{1}{p_{z}}+\frac{\tau}{p_{z}(q+\underline{q})} c_{\Delta}$. Therefore, $m^{Z} \leq R$ if and only if $c_{\Delta} \leq T_{2}$. If $c_{\Delta} \geq T_{1}$, then from Lemma 3 we have $r_{2}=r_{1}$ and $m^{Z}=c_{\Delta}+\frac{2-(q+q)}{2 p_{z}-\tau}$. Therefore, $m^{z} \leq R$ if and only if $c_{\Delta} \leq T_{3}$. To complete the proof we consider the following two cases:

(a) If $R \leq \frac{2}{2 p_{z}-\tau}$ then $T_{1} \geq T_{3} \geq T_{2}$ which in turn implies that $T_{1} \geq \max \left(T_{2}, T_{3}\right)$. In this case, if $c_{\Delta}>T_{1}$, then $c_{\Delta}>T_{3}$ and thus finance is not feasible. If $c_{\Delta} \leq T_{1}$, finance is feasible if $c_{\Delta} \leq T_{2}$. Therefore, if $R \leq \frac{2}{2 p_{z}-\tau}$ finance is feasible if and only if $c_{\Delta} \leq T_{2}=\min \left(T_{2}, T_{3}\right)$.

(b) If $R \geq \frac{2}{2 p_{z}-\tau}$ then $T_{1} \leq T_{3} \leq T_{2}$ which in turn implies that $T_{1} \leq \min \left(T_{2}, T_{3}\right)$. In this case, if $c_{\Delta} \leq T_{1}$, then $c_{\Delta} \leq T_{2}$. Thus finance is feasible. If $c_{\Delta}>T_{1}$, then finance is feasible if and only if $c_{\Delta} \leq T_{3}$. Therefore, in this case, finance is feasible if and only if $c_{\Delta} \leq T_{3}=\min \left(T_{2}, T_{3}\right)$. QED

Proposition 1 follows directly from Lemma 3 and Lemma 4. QED

\section{Proof of Proposition 2}

Let $m^{S}$ denote the optimal symmetric solution for $m$. (A1) and (A2), namely IC1 and IC2, are also constraints for this problem. We also need to add IC4 which can be written as 


$$
\begin{aligned}
(\underline{q}(\underline{q}-q)+(1-\underline{q})(q-\underline{q}))\left(m^{S}-r_{1}\right)+\underline{q}(q-\underline{q})\left(2 m^{S}-r_{2}\right) & \geq c \Longleftrightarrow \\
(1-2 \underline{q})\left(m^{S}-r_{1}\right)+\underline{q}\left(2 m^{S}-r_{2}\right) & \geq c_{\Delta} \Longleftrightarrow \\
m^{S}-(1-2 \underline{q}) r_{1}+\underline{q}_{2} & \geq c_{\Delta} .
\end{aligned}
$$

And $\mathrm{PC} 2$ which can be written as:

$$
2 p_{s}\left(1-p_{s}\right) r_{1}+p_{s}^{2} r_{2} \geq 2
$$

The problem of the two entrepreneurs is to

$$
\begin{aligned}
& \min _{m^{Z}, r_{1}, r_{2}} m^{S} \text {, s.t.(A1), (A2), (A6) and (A7); and } \\
& 0 \leq r_{1} \leq m^{S} \leqslant R, 0 \leq r_{2} \leq 2 m^{S} .
\end{aligned}
$$

Lemma 5 (A6) is binding.

Proof. Notice that (A6) implies (A2) if and only if

$$
\begin{aligned}
& (1-2 \underline{q})\left(m^{S}-r_{1}\right)+\underline{q}\left(2 m^{S}-r_{2}\right) \leq(1-q-\underline{q})\left(m^{S}-r_{1}\right)+\frac{q+\underline{q}}{2}\left(2 m^{S}-r_{2}\right) \Longleftrightarrow \\
& (q-\underline{q})\left(m^{S}-r_{1}\right) \leq \frac{q-\underline{q}}{2}\left(2 m^{S}-r_{2}\right) \Longleftrightarrow r_{1} \geq \frac{r_{2}}{2} .
\end{aligned}
$$

Thus, if $r_{1} \geq \frac{r_{2}}{2}$, then (A6) implies (A2) which, in turn, implies (A1) and vice versa. We first consider the case $r_{1} \leq \frac{r_{2}}{2}$. Following a similar argument as the one used for the proof of Proposition 1, we find that the problem of the two entrepreneurs is equivalent to

$$
\min H^{1}=(1-2 q) r_{1}+q r_{2} \text { subject to (A7). }
$$

From the binding (A7) it follows that $d r_{2}=-\frac{2\left(1-p_{s}\right)}{p_{s}} d r_{1}$. Then $d H^{2}=\left[(1-2 q)-q \frac{2\left(1-p_{s}\right)}{p_{s}}\right] d r_{1}$. Next, we show that the expression in the square brackets is negative: $1-2 q<q \frac{2\left(1-p_{s}\right)}{p_{s}} \Longleftrightarrow p_{s}<2 q$, which clearly holds. Thus $\frac{d H^{2}}{d r_{1}}<0$ for $r_{1} \leq \frac{r_{2}}{2}$ and the solution for this case is $r_{1}=\frac{r_{2}}{2}$. Therefore, the optimal solution for Problem 2 must lie in the region $r_{1} \geq \frac{r_{2}}{2}$. This implies (A6) is binding. QED

Therefore,

$$
m^{S}=(1-2 \underline{q}) r_{1}+\underline{q} r_{2}+c_{\Delta},
$$

and the problem of the two entrepreneurs is

$$
\min H^{3}=(1-2 \underline{q}) r_{1}+\underline{q} r_{2} \text { subject to }(\mathrm{A} 7)
$$


Lemma 6 (a) If $q / \underline{q} \geq(1+p) / p$, then $r_{1}=\frac{1}{p_{s}}, r_{2}=\frac{2}{p_{s}}, m^{S}=c_{\Delta}+\frac{1}{p_{s}}$.

(b) If $q / \underline{q}<(1+p) / p$, then

(i) if $c_{\Delta} \leq \frac{2 q}{p_{s}\left(1-p_{s}\right)}$ then $r_{1}=m^{S}=\frac{1}{p_{s}}+\frac{p_{s}}{2 \underline{q}} c_{\Delta}, r_{2}=\frac{2}{p_{s}}-\frac{1-p_{s}}{\underline{q}} c_{\Delta}$, and

(ii) if $c_{\Delta}>\frac{2 q}{p_{s}\left(1-p_{s}\right)}$ then $r_{1}=r_{2}=\frac{2}{2 p_{s}-p_{s}^{2}}, m^{s}=c_{\Delta}+\frac{2(1-\underline{q})}{2 p_{s}-p_{s}^{2}}$.

Proof. From the binding (A7) we get $d H^{3}=\left[(1-2 \underline{q})-\underline{q} \frac{2\left(1-p_{s}\right)}{p_{s}}\right] d r_{1}$. The expression in the square brackets has the same sign as:

$$
p_{s}-2 \underline{q}=p q+(1-p) \underline{q}-2 \underline{q}=\frac{q}{\underline{q}}-\frac{1+p}{p} .
$$

We need to consider two cases:

(a) Suppose that $\frac{q}{q}>\frac{1+p}{p}$. Then $\frac{d H^{3}}{d r_{1}}>0$. It is optimal to set $r_{1}$ as small as possible, which, in the region of $r_{1} \geq \frac{r_{2}}{2}$, implies that $r_{1}=\frac{r_{2}}{2}$. Using (A7) we get $r_{1}=\frac{1}{p_{s}}$. Then $r_{2}=\frac{2}{p_{s}}$. It follows that $m^{S}=(1-2 \underline{q}) r_{1}+\underline{q} r_{2}+c_{\Delta}=c_{\Delta}+\frac{1}{p_{s}}$.

(b) Suppose that $\frac{q}{q} \leq \frac{1+p}{p}$. Then $\frac{d H^{3}}{d r_{1}} \leq 0$. It is optimal to set $r_{1}$ as large as possible. Therefore, we go back to the solution of Problem 1. Following the same procedure we find the result given above.

This completes the proof of the lemma. QED

Therefore, so long as finance is feasible, that is the limited liability constraint of the two entrepreneurs is satisfied, the solution given in Lemma 7 is the solution to Problem 2. Now we are left to check the feasibility of finance, namely, when the satisfaction of constraint $m^{S} \leq R$. Let $T_{4} \equiv \frac{2 q}{2 p_{s}-p_{s}^{2}}$, $T_{5} \equiv \frac{2 q}{p_{s}}\left(R-\frac{1}{p_{s}}\right)$ and $T_{6} \equiv R-\frac{2(1-\underline{q})}{2 p_{s}-p_{s}^{2}}$. Then we have the following result:

Lemma 7 (a) If $q / \underline{q} \geq(1+p) / p$ then finance is feasible if and only if $c_{\Delta} \leq R-\frac{1}{p_{s}}$.

(b) If $q / \underline{q}<(1+p) / p$ then finance is feasible if and only if $c_{\Delta} \leq \min \left(T_{5}, T_{6}\right)$.

Proof. (a) Given that $m^{S}=c_{\Delta}+\frac{1}{p_{s}} \leq R$, finance is feasible if and only if $c_{\Delta} \leq R-\frac{1}{p_{s}}$.

(b) If $c_{\Delta} \leqslant T_{4}$, that is $\mathrm{MC}$ is satisfied, in which case $m^{S}=\frac{1}{p_{s}}+\frac{p_{s}}{2 \underline{q}} c_{\Delta}$, finance is feasible if and only if $c_{\Delta} \leq T_{5}$. If $c_{\Delta}>T_{4}$, in which case $m^{S}=c_{\Delta}+\frac{2(1-q)}{2 p_{s}-p_{s}^{2}}$, finance is feasible if and only if $c_{\Delta} \leq T_{6}$. It is straightforward to check that if $R \leq \frac{2}{2 p_{s}-p_{s}^{2}}$ then $T_{4} \geq T_{6} \geq T_{5}$ and if $R>\frac{2}{2 p_{s}-p_{s}^{2}}$ then $T_{4} \leq T_{6} \leq T_{5}$. By following exactly the same steps as those used for the proof of Lemma 4 we can show that finance is feasible if and only if $c_{\Delta} \leq \min \left(T_{5}, T_{6}\right)$.

This completes the proof. QED

Proposition 3 follows directly from Lemma 7 and Lemma 8. QED 


\section{Proof of Theorem 1}

Result (i) and results (ii) (a)-(c) follow directly from Propositions 1 and 2. Result (ii) (d) is concerned with the situation where both organization structures are feasible. In this situation, Bank is dominated by Fund if the entrepreneurs get more from the former than they do from the latter, that is, if $V^{Z}<V^{S}$. Recall that $m^{Z}$ is the optimal value of $m$ under Bank (case 1 at subsection 3.1), $m^{S}$ being that under Fund (case 2(ii) at subsection 3.2). Under Bank, a project ex ante succeeds with probability $p_{z}=p^{2} q+\left(1-p^{2}\right) \underline{q}$. When a project succeeds its entrepreneur pays $m^{Z}$ to $\mathrm{M}$ and keeps $R-m^{Z}$ for himself. Therefore, under Bank each entrepreneur's expected payoff is equal to $V^{Z}=p_{z}\left(R-m^{Z}\right)$. Similarly, under Fund, each entrepreneur's expected payoff is equal to $V^{S}=p_{s}\left(R-m^{S}\right)$. Thus, $V^{Z}<V^{S}-$ namely, Bank is dominated by Fund - if and only if

$$
\begin{aligned}
p_{z}\left(R-m^{Z}\right) & <p_{s}\left(R-m^{S}\right) \Longleftrightarrow \\
p_{z}\left(R-\max \left(\frac{1}{p_{z}}+\frac{\tau}{p_{z}(q+\underline{q})} c_{\Delta}, c_{\Delta}+\frac{2-(q+\underline{q})}{2 p_{z}-\tau}\right)\right) & <p_{s}\left(R-\left(c_{\Delta}+\frac{1}{p_{s}}\right)\right) \Longleftrightarrow \\
p_{z}\left(R-\max \left(\frac{1}{p_{z}}+\frac{\tau}{p_{z}(q+\underline{q})} c_{\Delta}, c_{\Delta}+\frac{2-(q+\underline{q})}{2 p_{z}-\tau}\right)\right) & <p_{s}\left(R-\left(c_{\Delta}+\frac{1}{p_{s}}\right) \Longleftrightarrow\right. \\
p_{s} c_{\Delta}+1-\max \left(1+\frac{\tau}{(q+\underline{q})} c_{\Delta}, p_{z} c_{\Delta}+\frac{p_{z}(2-(q+\underline{q}))}{2 p_{z}-\tau}\right) & <\left(p_{s}-p_{z}\right) R \Longleftrightarrow \\
\min \left(p_{s} c_{\Delta}+1-\left(1+\frac{\tau}{(q+\underline{q})} c_{\Delta}\right), p_{s} c_{\Delta}+1-\left(p_{z} c_{\Delta}+\frac{p_{z}(2-(q+\underline{q}))}{2 p_{z}-\tau}\right)\right) & <\left(p_{s}-p_{z}\right) R \Longleftrightarrow \\
\min \left(\frac{\left(p_{s}-p_{z}\right)(q+\underline{q})+q \underline{q}}{\left(p_{s}-p_{z}\right)(q+\underline{q})} c_{\Delta}, c_{\Delta}+\frac{q \underline{q}}{\left(p_{s}-p_{z}\right)\left(2 p_{z}-\tau\right)}\right) & <R .
\end{aligned}
$$

QED

\section{Proof of Corollary 1}

The corollary follows from two claims which hold under the conditions: (a) $\min \left(\frac{q+q}{\tau}\left(p_{z} R-1\right), R-\frac{2-(q+q)}{2 p_{z}-\tau},\right)<$ $R-\frac{1}{p_{s}}$, which implies that if finance is feasible under only one structure, then it is Fund; and (b) (A8) holds if $c_{\Delta}<\min \left(\frac{q+\underline{q}}{\tau}\left(p_{z} R-1\right), R-\frac{2-(q+\underline{q})}{2 p_{z}-\tau}\right)$, which implies that if finance is feasible under both structures, then Fund dominates Bank. 
For claim (a): It is implied by $\frac{2-(q+\underline{q})}{2 p_{z}-\tau}>\frac{1}{p_{s}}$, which holds true if $q \underline{q}<\left(p_{s}-p_{z}\right)(2-(q+\underline{q}))$, because

$$
\begin{aligned}
\frac{1}{p_{s}} & <\frac{2-(q+\underline{q})}{2 p_{z}-\tau} \Longleftrightarrow \\
2 p_{z}-\tau & <2 p_{s}-p_{s}(q+\underline{q}) \Longleftrightarrow \\
p_{s}(q+\underline{q})-\tau & <2\left(p_{s}-p_{z}\right) \Longleftrightarrow \\
p_{s}(q+\underline{q})-p_{z}(q+\underline{q})+p_{z}(q+\underline{q})-\tau & <\left.2\left(p_{s}-p_{z}\right)\right|_{\tau \equiv p^{2} q^{2}+\left(1-p^{2}\right) \underline{q}^{2}} \Longleftrightarrow \\
\left(p_{s}-p_{z}\right)(q+\underline{q})+q \underline{q} & <2\left(p_{s}-p_{z}\right) \Longleftrightarrow \\
q \underline{q} & <\left(p_{s}-p_{z}\right)(2-(q+\underline{q})) .
\end{aligned}
$$

For claim (b): If $c_{\Delta}<\min \left(\frac{q+\underline{q}}{\tau}\left(p_{z} R-1\right), R-\frac{2-(q+\underline{q})}{2 p_{z}-\tau}\right)$, then $\min \left(\frac{\left(p_{s}-p_{z}\right)(q+\underline{q})+q \underline{q}}{\left(p_{s}-p_{z}\right)(q+\underline{q})} c_{\Delta}, c_{\Delta}+\frac{q \underline{q}}{\left(p_{s}-p_{z}\right)\left(2 p_{z}-\tau\right)}\right) \leq$ $c_{\Delta}+\frac{q \underline{q}}{\left(p_{s}-p_{z}\right)\left(2 p_{z}-\tau\right)}<\min \left(\frac{q+\underline{q}}{\tau}\left(p_{z} R-1\right)+\frac{q \underline{q}}{\left(p_{s}-p_{z}\right)\left(2 p_{z}-\tau\right)}, R-\frac{2-(q+\underline{q})}{2 p_{z}-\tau}+\frac{q \underline{q}}{\left(p_{s}-p_{z}\right)\left(2 p_{z}-\tau\right)}\right) \leq R-\frac{2-(q+\underline{q})}{2 p_{z}-\tau}+$ $\frac{q \underline{q}}{\left(p_{s}-p_{z}\right)\left(2 p_{z}-\tau\right)}$. Therefore, claim (b) - that (A8) holds - follows from the fact that $-\frac{2-(q+\underline{q})}{2 p_{z}-\tau}+\frac{q \underline{q}}{\left(p_{s}-p_{z}\right)\left(2 p_{z}-\tau\right)}<$ 0 , which holds true if $q \underline{q}<\left(p_{s}-p_{z}\right)(2-(q+\underline{q}))$, because

$$
\begin{aligned}
\frac{q \underline{q}}{\left(p_{s}-p_{z}\right)\left(2 p_{z}-\tau\right)} & <\frac{2-(q+\underline{q})}{2 p_{z}-\tau} \Leftrightarrow \\
\frac{q \underline{q}}{\left(p_{s}-p_{z}\right)} & <2-(q+\underline{q}) \Leftrightarrow \\
q \underline{q} & <\left(p_{s}-p_{z}\right)(2-(q+\underline{q})) .
\end{aligned}
$$

QED

\section{Proof of Proposition 3}

As in the case with intermediated finance, the entrepreneurs may prefer M to monitor only when both projects are type $h$, or they may prefer him to monitor any project as long as it is type $h$. For each case, we first figure out the optimal arrangement under direct finance and then compare it with the optimal financial intermediation arrangement. Let $m^{d}$ (the superscript $d$ denotes 'direct finance') denote the payment to $\mathrm{M}$ from an entrepreneur whose project succeeds.

Lemma 8 If the entrepreneurs would like $M$ to monitor only when both projects are type $h$, then the optimal (and only feasible) contract is $m^{d}=c_{\Delta}$. 
Proof. The problem for each entrepreneur is to choose the lowest value of $m^{d}$ that satisfies the following constraints that are the counterparts of constraints IC1, IC2 and IC3 of Problem 1:

$$
\begin{aligned}
2 q^{2} m^{d}+2 q(1-q) m^{d}-2 c & \geq 2 q \underline{q} m^{d}+[q(1-\underline{q})+\underline{q}(1-q)] m^{d}-c \Longleftrightarrow \\
m^{d} \geq c_{\Delta} & \\
2 q^{2} m^{d}+2 q(1-q) m^{d}-2 c & \geq 2 \underline{q}^{2} m^{d}+2 \underline{q}(1-\underline{q}) m^{d} \Longleftrightarrow \\
m^{d} & \geq c_{\Delta}
\end{aligned}
$$

and

$$
\begin{aligned}
2 \underline{q}(1-\underline{q}) m^{d}+\underline{q}^{2} 2 m^{d} & \geq[\underline{q}(1-q)+q(1-\underline{q})] m^{d}+q \underline{q} 2 m^{d}-c \Longleftrightarrow \\
2 \underline{q} m^{d} & \geq(\underline{q}+q) m^{d}-c \Longleftrightarrow m^{d} \leq c_{\Delta} .
\end{aligned}
$$

Here (A9) requires that if both are type $h$ projects, $M$ prefers to monitor both of them rather than only one project, or rather than neither if (A10) holds; and (A11) requires that if only one project is type $h$, $\mathrm{M}$ is disincentivized to monitor it. The above three inequalities imply that the only feasible contract is $m^{d}=c_{\Delta} . \mathrm{QED}$

Lemma 9 If the entrepreneurs would like $M$ to monitor a project whenever it is good, then the optimal contract is $m^{d}=c_{\Delta}$.

Proof. The problem for the two entrepreneurs is to choose the lowest value of $m^{d}$ that satisfies (A9), (A10) and the inverse of (A11), which is

$$
\begin{aligned}
{[\underline{q}(1-q)+q(1-\underline{q})] m^{d}+q \underline{q} 2 m^{d}-c } & \geq 2 \underline{q}(1-\underline{q}) m^{d}+\underline{q}^{2} 2 m^{d} \Longleftrightarrow \\
(\underline{q}+q) m^{d}-c & \geq 2 \underline{q} m^{d} \Longleftrightarrow m^{d} \geq c_{\Delta},
\end{aligned}
$$

where (A12) requires that if only one project is type $h, \mathrm{M}$ is incentivized to monitor it. The entrepreneurs' problem becomes

$$
\min m^{d} \text {, s.t. } m^{d} \geq c_{\Delta} .
$$

The solution is $m^{d}=c_{\Delta}$. QED

The two lemmas imply that the entrepreneurs want $\mathrm{M}$ to monitor a project whenever it is of type h. QED 


\section{Proof of Proposition 4}

If the internal control cost is bigger than $c$, then the monitors will not be monitored but we still need two monitors, call them M1 and M2 to monitor the two entrepreneurs. Thus, the only way to induce them to monitor is to offer them sufficient incentives. Consider problem 1. Suppose the incentive scheme for $\mathrm{M} k(k=1,2)$ is $m_{i j}^{k}$ where $i, j=1,0$ denote the success or failure of each of the two projects. Given that M2 monitors, M1 has an incentive to monitor if and only if $q(1-q) m_{10}^{1}+q(1-q) m_{01}^{1}+q^{2} m_{11}^{1}-c \geq$ $\underline{q}(1-q) m_{10}^{1}+(1-\underline{q}) q m_{01}^{1}+q \underline{q} m_{11}^{1}$. The last expression is equivalent to $(1-q) m_{10}^{1}-q m_{01}^{1}+q m_{11}^{1} \geq \frac{c}{q-\underline{q}}$. The optimal incentive scheme requires $m_{01}^{1}=0$; that is $\mathrm{M} 1$ is not compensated if his assigned project fails and M2's assigned project succeeds. Then $(1-q) m_{10}^{1}+q m_{11}^{1} \geq \frac{c}{q-\underline{q}}$. That means that if project 1 succeeds M1 expects at least $\frac{c}{q-\underline{q}}$, which is exactly what M1 gets under the Fund structure. QED

\section{Proof of Proposition 5}

We are going to prove the Proposition 5 in two steps. We will first demonstrate that with multilateral contracting, financial intermediation and direct finance implement the same set of allocations. Then we will prove that as long as $c_{\Delta} \leqslant \min \left(\frac{q+\underline{q}}{2 p_{z}-\tau}, \frac{2 q}{p_{s}\left(2-p_{s}\right)}\right)$ the the optimal arrangement of financial intermediation with bilateral contracting, as have been described in Propositions 1 and 2, implements the same allocation as the optimal arrangement of direct finance does with multilateral contracting.

Lemma 10 With multilateral contracting, financial intermediation and direct finance implement the same set of allocations.

Proof. Consider a direct finance arrangement whereby each entrepreneur signs contracts separately with M and investors. Denote the contracts agreed between each entrepreneur (E1 and E2) and M by $m_{i j}^{d k}$, where $k=1,2$ denotes the entrepreneur and $i, j=0,1$ denote the outcomes of the two projects. Thus, for example, $m_{10}^{d 1}$ is the payment from $\mathrm{E} 1$ to $\mathrm{M}$ when project 1 succeeds but project 2 fails. Treating symmetrically the two entrepreneurs and taking into account their limited liability implies that the general contract can be written as $\left(m_{1}^{d}, m_{2}^{d}\right)$, where $m_{1}^{d}$ is the payment to $\mathrm{M}$ if only one project succeeds (received from the successful entrepreneur) and $m_{2}^{d}$ is the payment from each entrepreneur if both projects succeed. Similarly, a general contract to investors can be denoted by $\left(r_{1}^{d}, r_{2}^{d}\right)$, where $r_{1}^{d}$ is the payment to the investors if only one project succeeds (received from the successful entrepreneur) and $r_{2}^{d}$ is the payment from each entrepreneur to investors if both projects succeed. 
Consider the arrangement under financial intermediation with multilateral contracting. An assetside contract is $\left(m_{1}, m_{2}\right)$, where $m_{1}$ denotes the payment to $\mathrm{M}$ when only one project succeeds (received from the successful entrepreneur) and $m_{2}$ denotes the payment from each entrepreneur if both projects succeed. The contract on the liability side is still given by $\left(r_{1}, r_{2}\right)$.

Then, any arrangement under financial intermediation, $\left(m_{1}, m_{2} ; r_{1}, r_{2}\right)$, can be implemented by an arrangement under direct finance where $m_{1}^{d}=m_{1}-r_{1}$ and $m_{2}^{d}=m_{2}-r_{2} / 2 ; r_{1}^{d}=r_{1}$ and $r_{2}^{d}=$ $r_{2} / 2$. Moreover, any arrangement under direct finance, $\left(m_{1}^{d}, m_{2}^{d} ; r_{1}^{d}, r_{2}^{d}\right)$, can be implemented by an arrangement under financial intermediation where $m_{1}=r_{1}^{d}+m_{1}^{d}$ and $m_{2}=r_{2}^{d}+m_{2}^{d} ; r_{1}=r_{1}^{d}$ and $r_{2}=2 r_{2}^{d} . \mathrm{QED}$

Lemma 11 Suppose that $c_{\Delta} \leqslant \min \left(\frac{q+\underline{q}}{2 p_{z}-\tau}, \frac{2 q}{p_{s}\left(2-p_{s}\right)}\right)$. Then, Bank and Fund implement the same allocations as the optimal arrangement under direct finance with multilateral contracting.

Proof. The following observation is useful when considering the optimal arrangement under direct finance. Under direct finance the contract to investors, $\left(r_{1}^{d}, r_{2}^{d}\right)$, has no effect on the incentives of the monitor. Therefore, any contract such that the participation constraint of investors is binding is optimal from the point of view of entrepreneurs. Once more the two entrepreneurs might prefer $M$ to monitor only when both projects are type $h$ or to monitor a project so long as it is type $h$. For each case, we derive the optimal arrangement under direct finance and then show that it can be implemented by Bank or Fund with bilateral contracting if $c_{\Delta} \leqslant \min \left(\frac{q+\underline{q}}{2 p_{z}-\tau}, \frac{2 q}{p_{s}\left(2-p_{s}\right)}\right)$.

Result 1: If the entrepreneurs would like $M$ to monitor only when both projects are type $h$, then the optimal arrangement is $m_{1}^{d}=0, m_{2}^{d}=\frac{c_{\Delta}}{q+\underline{q}}$.

Proof: A feasible arrangement under direct finance must satisfy the limited liability constraint, namely that $m_{1}^{d} \geq 0$ and $m_{2}^{d} \geq 0$, and the $\mathrm{IC}$ constraints that require that $\mathrm{M}$ has incentives to monitor if and only if both projects are good (i.e. type $h$ ). The following incentive constraint states that when both projects are good, $\mathrm{M}$ prefers to monitor both rather than only one of them:

$$
\begin{aligned}
2 q^{2} m_{2}^{d}+2 q(1-q) m_{1}^{d}-2 c & \geq 2 q \underline{q} m_{2}^{d}+[q(1-\underline{q})+\underline{q}(1-q)] m_{1}^{d}-c \Longleftrightarrow \\
(1-2 q) m_{1}^{d}+2 q m_{2}^{d} & \geq c_{\Delta}
\end{aligned}
$$


The following incentive constraint states that when both projects are good, M prefers to monitor both of them rather than none:

$$
\begin{aligned}
2 q^{2} m_{2}^{d}+2 q(1-q) m_{1}^{d}-2 c & \geq 2 \underline{q}^{2} m_{2}^{d}+2 \underline{q}(1-\underline{q}) m_{1}^{d} \Longleftrightarrow \\
(1-q-\underline{q}) m_{1}^{d}+(q+\underline{q}) m d_{2}^{d} & \geq c_{\Delta}
\end{aligned}
$$

There is additional constraint ensuring that when only one project is good, M prefers not to monitor it, which, we can show, is not binding at the optimum, following the same argument as the one used for the proof of Proposition 1. At date 0, the expected payment to $\mathrm{M}$ from each entrepreneur is equal to

$$
p^{2}\left(q^{2} m_{2}^{d}+q(1-q) m_{1}^{d}\right)+\left(1-p^{2}\right)\left(\underline{q}^{2} m_{2}^{d}+\underline{q}(1-\underline{q}) m_{1}^{d}\right)=\gamma m_{1}^{d}+\tau m_{2}^{d}
$$

where $\gamma=p^{2} q(1-q)+\left(1-p^{2}\right) \underline{q}(1-\underline{q})$ and $\tau=p^{2} q^{2}+\left(1-p^{2}\right) \underline{q}^{2}$.

Thus the optimal mechanism solves the problem

$$
\min H^{4}=\gamma m_{1}^{d}+\tau m_{2}^{d} \text { subject to (A13) and (A14) }
$$

(A14) implies (A13) if and only if $m_{1}^{d} \leq m_{2}^{d}$. First, consider the case $m_{1}^{d} \geq m_{2}^{d}$, which implies that (A13) is binding and thus $d m_{2}^{d}=-\frac{1-2 q}{2 q} d m_{1}^{d}$. Then $d H^{4}=\gamma d m_{1}^{d}+\tau d m_{2}^{d}=\left[\gamma-\tau \frac{1-2 q}{2 q}\right] d m_{1}^{d}$. In the proof of Proposition 1, we have shown that the expression in the brackets is positive and thus $\frac{d H^{4}}{d m_{1}^{d}}>0$. Thus the solution for this case is to set $m_{1}^{d}=m_{2}^{d}$ which implies that the optimal solution to the above problem is in the region $m_{1}^{d} \leq m_{2}^{d}$. Next, consider the case $m_{1}^{d} \leq m_{2}^{d}$, which implies that (A14) is binding and thus $d m_{2}^{d}=-\frac{(1-q-\underline{q})}{q+\underline{q}} d m_{1}^{d}$. Then $d H^{4}=\gamma d m_{1}^{d}+\tau d m_{2}^{d}=\left[\gamma-\tau \frac{(1-q-\underline{q})}{q+\underline{q}}\right] d m_{1}^{d}$. In the proof of Proposition 1, we have shown that $1-q-\underline{q}<(q+\underline{q}) \frac{\gamma}{\tau}$, which implies $\gamma-\tau \frac{(1-q-\underline{q})}{q+\underline{q}}>0$. Thus $\frac{d H^{4}}{d m_{1}^{d}}>0$, which, in turn, implies that it is optimal to set $m_{1}^{d}=0$. QED

Result 2: The optimal allocation under direct finance given by Result $1,\left(m_{1}^{d}=0, m_{2}^{d}=\frac{c_{\Delta}}{q+\underline{q}}\right)$, can be implemented by Bank if and only if $c_{\Delta} \leq \frac{q+q}{2 p_{z}-\tau}$.

Proof: An arrangement under financial intermediation $\left(m ; r_{1}, r_{2}\right)$ implements an allocation under direct finance $\left(m_{1}^{d}, m_{2}^{d}\right)$ if and only if

$$
\begin{aligned}
m-r_{1} & =m_{1}^{d} \\
2 m-r_{2} & =2 m_{2}^{d}
\end{aligned}
$$

and the $\mathrm{PC}$ of investors

$$
\left[p^{2} q(1-q)+\left(1-p^{2}\right) \underline{q}(1-\underline{q})\right] 2 r_{1}+\left[p^{2} q^{2}+\left(1-p^{2}\right) \underline{q}^{2}\right] r_{2}=2 .
$$


When $m_{1}^{d}=0 ; m_{2}^{d}=\frac{c_{\Delta}}{q+\underline{q}}$, these three equations give $m=\frac{1}{p_{z}}+\frac{\tau}{p_{z}(q+\underline{q})} c_{\Delta}=r_{1}$ and $r_{2}=\frac{2}{p_{z}}\left(1-\frac{p_{z}-\tau}{q+\underline{q}} c_{\Delta}\right)$. This is the arrangement of Bank by Proposition 1 if and only if $c_{\Delta} \leq \frac{q+q}{2 p_{z}-\tau}$. QED

Result 3: Suppose the entrepreneurs would like $M$ to monitor a project whenever it is type $h$. Then if $q / \underline{q}<(1+p) / p$, the optimal direct arrangement is $\left(m_{1}^{d}=0, m_{2}^{d}=c_{\Delta} /(2 \underline{q})\right)$, otherwise it is given by $m_{1}^{d}=m_{2}^{d}=c_{\Delta}$.

Proof: In addition to constraints (A13) and (A14), the IC constraints include the following one which states that when only one project is good M prefers to monitor it:

$$
\begin{aligned}
& (\underline{q}(1-q)+q(1-\underline{q})) m_{1}^{d}+q \underline{q} 2 m_{2}^{d}-c \geq \underline{q}(1-\underline{q}) 2 m_{1}^{d}+\underline{q}^{2} 2 m_{2}^{d} \Longleftrightarrow \\
& (\underline{q}(\underline{q}-q)+(1-\underline{q})(q-\underline{q})) m_{1}^{d}+\underline{q}(q-\underline{q}) 2 m_{2}^{d} \geq c \Longleftrightarrow \\
& (1-2 \underline{q}) m_{1}^{d}+\underline{q} 2 m_{2}^{d} \geq c_{\Delta}
\end{aligned}
$$

Thus the optimal mechanism solves the problem

$$
\min H^{4}=\gamma m_{1}^{d}+\tau m_{2}^{d} \text { subject to (A13), (A14) and (A17) }
$$

Notice that (A17) implies (A14) which in turn implies (A13) if and only if $m_{1}^{d} \leq m_{2}^{d}$ and vice versa. We first consider the case $m_{1}^{d} \geq m_{2}^{d}$ which implies that (A13) is binding and thus $d m_{2}^{d}=-\frac{1-2 q}{2 q} d m_{1}^{d}$. Following the same steps as in Result 1 we find that it is optimal to set $m_{1}^{d}=m_{2}^{d}$. Therefore, the optimal solution for the above problem must lie in the region $m_{1}^{d} \leq m_{2}^{d}$ which implies that (A17) is binding and thus $d m_{2}^{d}=-\frac{1-2 q}{2 \underline{q}} d m_{1}^{d}$. Then $d H^{4}=\gamma d m_{1}^{d}+\tau d m_{2}^{d}=\left[\gamma-\tau \frac{1-2 q}{2 \underline{q}}\right] d m_{1}^{d}$. The expression in the brackets has the same sign as $(1+p) / p-q / \underline{q}$, and, thus, we need to consider two cases.

(a) Suppose that $q / \underline{q}<(1+p) / p$. Then $\frac{d H^{4}}{d m_{1}^{d}}>0$ in which case it is optimal to set $m_{1}^{d}$ as small as possible, that is, $m_{1}^{d}=0$. It follows from binding (A17) that $m_{2}^{d}=c_{\Delta} /(2 \underline{q})$.

(b) Suppose that $q / \underline{q} \geq(1+p) / p$ which implies that $\frac{d H^{4}}{d m_{1}^{d}} \geq 0$. Now it is optimal to set $m_{1}^{d}$ as large as possible, which, given that $m_{1}^{d} \leq m_{2}^{d}$, it implies that $m_{1}^{d}=m_{2}^{d}$. By substituting $m_{1}^{d}=m_{2}^{d}$ into the binding (A17), we find that $m_{1}^{d}=m_{2}^{d}=c_{\Delta}$. QED

Result 4: If $q / \underline{q}<(1+p) / p$, the optimal allocation under direct finance can be implemented by Bank if and only if $c_{\Delta} \leq \frac{2 q}{p_{s}\left(2-p_{s}\right)}$. If $q / \underline{q} \geq(1+p) / p$, the optimal allocation under direct finance can be implemented by Fund.

Proof: Similarly to the proof of Result 2, to implement a direct finance allocation $\left(m_{1}^{d}, m_{2}^{d}\right)$, the arrangement under financial intermediation, $\left(m ; r_{1}, r_{2}\right)$, shall satisfy (A15) and (A16). However, in this 
case participation constraint of investors is different, because as the probability of one project succeeding is $p_{s} ;\left(r_{1}, r_{2}\right)$ now satisfies:

$$
2 p_{s}\left(1-p_{s}\right) r_{1}+p_{s}^{2} r_{2}=2
$$

(a) If $q / \underline{q}<(1+p) / p$, the optimal allocation under direct finance is $\left(m_{1}^{d}=0, m_{2}^{d}=c_{\Delta} /(2 \underline{q})\right.$. The solution of the simultaneous equations of (A15), (A16) and (A18) is given by $r_{1}=m=\frac{1}{p_{s}}+\frac{p_{s}}{2 q} c_{\Delta}$, $r_{2}=\frac{2}{p_{s}}-\frac{1-p_{s}}{\underline{q}} c_{\Delta}$, which is the arrangement of Bank if and only if $c_{\Delta} \leq \frac{2 \underline{q}}{p_{s}\left(2-p_{s}\right)}$, by Lemma 6(b.i).

(b) If $q / \underline{q} \geq(1+p) / p$, the optimal allocation under direct finance is $m_{1}^{d}=m_{2}^{d}=c_{\Delta}$. Now the solution of those three equations is given by $r_{1}=r_{2} / 2=\frac{1}{p_{s}}$ and $m=\frac{1}{p_{s}}+c_{\Delta}$, which is the arrangement of Fund. QED

Lemma 11 follows from Results 2 and 4. QED

Proposition 5 follows from Lemma 10 and Lemma 11. QED.

\section{References}

[1] Bolton P. and M. Dewatripont (2005) Contract Theory,MIT Press, Cambridge.

[2] Cerasi V. and S. Daltung (2000) The Optimal Size of a Bank: Costs and Benefits of Diversification, European Economic Review 44, 1701-1726.

[3] Cuny C. and E. Talmor (2007) A Theory of Private Equity Turnarounds, Journal of Corporate Finance 13, 629-646.

[4] Diamond D. (1984) Financial Intermediation and Delegated Monitoring, Review of Economic Studies 51, 393-414.

[5] Fenn G., N. Liang and S. Prowse (1995) The Economics of the Private Equity Market, Board of Governors Federal Reserve Report No. 168.

[6] Freixas X. and J.-C. Rochet (2008) Micoeconomics of Banking, MIT Press, Cambridge.

[7] Gale D. and M. Hellwig (1985) Incentive-Compatibility Debt Contracts: The One-Period Problem, Review of Economic Studies 52, 647-663.

[8] Gompers P. (1995) Optimal Investment, Monitoring, and the Staging of Venture Capital, Journal of Finance 50, 1461-1489. 
[9] Gorton G. and G. Pennacchi (1990) Financial Intermediaries and Liquidity Creation, Journal of Finance 45, 49-71.

[10] Gorton G. and A. Winton (2003) Financial Intermediation, in G. Constantinides, M. Harris and R. Stulz (eds.) Handbook of the Economics of Finance, North-Holland, Amsterdam, 431-552.

[11] Greenbaum S. and A. Thakor (2007) Contemporary Financial Intermediation, Academic Press, New York.

[12] Hellwig M. (2000) Financial Intermediation with Risk Aversion, Review of Economic Studies 67, 719-742.

[13] Holmström B. and J. Tirole (1997) Financial Intermediation, Loanable Funs, and the Real Sector, Quarterly Journal of Economics 112, 663-692.

[14] Innes R. (1990) Limited Liability and Incentive Contracting with Ex-Ante Choices, Journal of Economic Theory, 52, 45-67.

[15] Kerr W., R. Nanda and M. Rhodes-Kropf (2014) Entrepreneurship as Experimentation, Journal of Economic Perspectives 28, 25-48.

[16] Krasa S. and A. Villamil (1992) Monitoring the Monitor: An Incentive Structure for a Financial Intermediary, Journal of Economic Theory 57, 197-221.

[17] Laffont J.-J. and D. Martimont (2002) The Theory of Incentives: The Principal Agent Model, Princeton University Press, Princeton.

[18] Laux C. (2001) Limited-Liability and Incentive Contracting with Multiple Projects, Rand Journal of Economics 32, 514-526.

[19] Metrick A. and A. Yasuda (2010) The Economics of Private Equity Funds, Review of Financial Studies, 23, 2303-2341.

[20] Sahlman W. (1990) The Structure and Governance of Venture-Capital Organizations, Journal of Financial Economics 27, 473-521.

[21] Tirole J. (2006) The Theory of Corporate Finance, Princeton University Press, Cambridge, MI, US. 
[22] Townsend R. (1979) Optimal Contracts and Competitive Markets with Costly State Verification, Journal of Economic Theory 21, 265-293.

[23] Wang T. (2012) The Allocation of Liability, Delegated Monitoring, and Modes of Financing, University of Essex, Mimeo.

[24] Williamson S. (1986) Costly Monitoring, Financial Intermediation, and Equilibrium Credit Rationing, Journal of Monetary Economics 18, 159-179.

[25] Winton A. (1995) Delegated Monitoring and Bank Structure in a Finite Economy, Journal of Financial Intermediation 4, 158-187. 